Original Research Paper

\title{
Spatial-Temporal Analysis of Temperature Trend and its Possible Effects on Water Resources and Water Uses in Climatic Zones of Iran's Zayandehrud River Basin
}

\author{
${ }^{1}$ Ali Zahraei, ${ }^{2}$ Saeid Eslamian, ${ }^{3}$ Sara Saadati, ${ }^{4}$ Mohsen Nekooei, ${ }^{5}$ Ali Heidarian, ${ }^{6}$ Kaveh Ostad-Ali-Askari, \\ ${ }^{7}$ Ali Hasantabar-Amiri and ${ }^{8}$ Mohammad Mousavi \\ ${ }^{I}$ Department of Irrigation and Drainage Engineering, University of Tehran, Tehran, Iran \\ ${ }^{2}$ Department of Water Engineering, College of Agriculture, Isfahan University of Technology, Isfahan, Iran \\ ${ }^{3}$ Department of Natural Resources Engineering, Isfahan University of Technology, Isfahan, Iran \\ ${ }^{4}$ Department of Water Engineering, College of Agriculture, Isfahan University of Technology, Isfahan, Iran \\ ${ }^{5}$ Department of Water Engineering, College of Agriculture, Isfahan University of Technology, Isfahan, Iran \\ ${ }^{6}$ Department of Civil Engineering, Isfahan (Khorasgan) Branch, Islamic Azad University, Isfahan, Iran \\ ${ }^{7}$ Department of Civil Engineering, Lenjan Branch, Islamic Azad University, Lenjan, Iran \\ ${ }^{8}$ Department of Civil Engineering, Najafabad Branch, Islamic Azad University, Najafabad, Iran
}

Article history

Received: 22-12-2018

Revised: 28-02-2019

Accepted: 26-06-2019

Corresponding Author:

Kaveh Ostad-Ali-Askari

Department of Civil

Engineering, Isfahan

(Khorasgan) Branch, Islamic

Azad University, Isfahan, Iran

Email: Kaveh.oaa2000@gmail.com
Abstract: The minimum, moderate and maximum temperature trends at seasonal time scale in 5 climatic zones using 37 meteorological stations in Zayandehrud river basin was studied regionally and the relationship to water resources, water uses of each zone and its possible effects were determined. The results showed that the majority of the climatic zones will have an increasing trend in spring, summer and fall and a decreasing trend in winter. The highest growth rate occurs in overnight temperature in spring and summer and daily temperature in fall. In winter, there is no significant difference between the slopes of temperature variables trend. The Most increasing slopes of the trend are seen in the northern part of the basin and during summer and the least decreasing slopes are in the northern and North-western parts of the basin during winter. The temperature rise in fall, spring and summer affect the reduction of water resources and increasing consumption in different areas. Among the various zones, the Eastern part of the basin will be faced with more water stress to meet their needs. The findings of this study can be effective for an identification of sensitive areas to climate change in the basin and planning to control water stress and achieving sustainable river basin management. Cloud coverage and rainfall associated defectively with the subtractive temperature span. Detailing long-term tendencys or determined moves in temperature and precipitation is significant for considerate the present and future alterations in nature. Monthly precipitation alterations may be optimistic or undesirable in various months of the year. While heating can possibly abridge the crop growth period, crop production and water efficiency of all crops are anticipated to reduction due to lower precipitation and higher water prerequisites under higher temperature. The Zayandeh-Rud River basin, Iran, is anticipated to encounter spatiotemporally heterogeneous temperature rise and precipitation decrease that will reduction water supply by mid-century. consequences propose that infrastructural recoveries, strict water request management and ecosystem-based regulatory prioritization, integrated by supply increase can temporarily reduce water stress in a basin.

Keywords: Temperature Trend, Zayandehrud River Basin, Regional Analysis, Climatic Zones

(C) 2019 Ali Zahraei, Saeid Eslamian, Sara Saadati, Mohsen Nekooei, Ali Heidarian, Kaveh Ostad-Ali-Askari, Ali Hasantabar-Amiri and Mohammad Mousav. This open access article is distributed under a Creative Commons Attribution (CC-BY) 3.0 license. 


\section{Introduction}

Greenhouse gas emission is rising due to the industrial revolution in the world from the 1900s. These gases prevent heat resulting from solar radiation reflected from the Earth's surface into space that will cause changes in energy balance and the gradual increase of global temperature (Takara et al., 2009). In this regard, the International Panel on Climate Change (IPCC) has shown that temperature of the Earth's surface increase by about $0.85^{\circ} \mathrm{C}$ during years $1880-2012$ and it is predicted to rise to $1.5-2^{\circ} \mathrm{C}$ by the end of the $21 \mathrm{st}$ century (IPCC, 2013). Global warming will increase evaporation and transpiration, which not only lead to reducing soil moisture and increasing the intensity and duration of droughts but will cause increasing amounts of water evaporates in the atmosphere and significant changes in the Earth's Hydrological cycle, including changes in the amount and pattern of rainfall (Xu et al., 2006; Zhang et al., 2008; 2010; Eslamian et al., 2012). Therefore, awareness of the impact of variations in hydrological parameters influenced by climate change, such as temperature, precipitation and evapotranspiration could help officials, designers and planners to manage water resources more efficiently in the future and make researchers curious to study historical evidence and parameters trends to predict the future. There are different types of research studies about temperature which many of them have reported an increase in temperature of the Earth's surface: Perez et al. (2000) by using 40 years old statistics showed the northern hemisphere, most of Europe, North America and the Atlantic Ocean has an incremental trend in temperature while the downward trend can be seen in Iceland, Greenland and the North East coast of Canada. Schlunzen et al. (2010) evaluated long-term changes in temperature and precipitation in Hamburg surrounding areas. The results showed that the average temperatures have risen significantly during $1891-2007\left(0.07^{\circ} \mathrm{k}\right), 1948$ $2007\left(0.19^{\circ} \mathrm{k}\right)$ and $1978-2007\left(0.6^{\circ} \mathrm{k}\right)$ and the greatest rise in temperature occurred in fall. Martinez et al. (2010) studied daily and nightly temperature trend using 37 stations date in the region of Catalonia (Spain) in the period 1975-2004. They showed the annual temperature has increased at an average of $0.5^{\circ} \mathrm{C}$ per decade and this increase occurred especially in summer and spring. Boccolari and Malmusi (2013) showed frost days have decreased during 30 years while the summer has increased by comparing extreme variations in temperature and rainfall in Modena, Italy. Wang et al. (2012) studied trend in annual temperatures and precipitation variations for a 50-year period in Loess Plateau Region (LPR) and showed that the average temperature of the region increased by $1.91^{\circ} \mathrm{C}$ during this period. Nie et al. (2012) evaluated Temporal and spatial variations in temperature and precipitation in Guangx and their results showed that the annual extreme temperature has increased over the period 1960-2009. Yue and Hashino (2003) analyzed the annual, seasonal and monthly temperature trends in Japan for the 100-year period and found temperature trend has increased from $0.51^{\circ} \mathrm{C}$ in 1900 to $2.77^{\circ} \mathrm{C}$ in 1996 . Grieser et al. (2002) studied temperature pattern in Europe during the 100-year period and the results showed a downward trend in annual temperature in Western Europe and incremental trend in Eastern Europe. Ahmed et al. (2014) evaluated trends of maximum and minimum temperatures for the period 1941-2005 in Ontario, Canada. According to their results, maximum temperature is rising in the seasonal and annual scale. Romero-Higareda et al. (2014) studied9 suggested temperature parameters for 71 stations in northwestern Mexico and showed heating trend in the first 6 months of the year. Also, they identified latitude as the most effective parameter for the spatial distribution of the trends of the slope. Studied the mean daily temperature and the maximum and minimum temperatures at 59 stations in Turkey during the period 1930-1993. Mean seasonal minimum temperatures indicated general warming trends especially in spring and Maximum temperatures showed general cooling in all seasons except spring for all of Turkey. Also, Turkes and Sumer (2004) reported a weak cooling and warming in $T_{\max }$ compared to a significant warming of $\mathrm{T}_{\min }$ in many regions of Turkey and for the most seasons. Hasanean (2001) studied temperature trends from 8 stations in the Eastern Mediterranean including Malta, Athens, Tripoli, Alexandria, Amman, Beirut, Jerusalem and Latakia. They found a significant positive trend for Malta, Jerusalem and Tripoli at the $99 \%$ confidence level and a negative trend for Amman at the 95\% confidence level.

Matouq et al. (2013) have studied the changes in mean and mean maximum and minimum temperatures and annual precipitation during the period 2008-2009 in Jordan and then used the results for forecasting the 20092018 period. In this study, GIS and neural network model were applied to analyze, simulate and predict in Matlab software. The findings of this study indicate that the mean local temperature in the last 50 years has increased from 1.5 to $2{ }^{\circ} \mathrm{C}$ rapidly since 1992 . In the prediction of temperature, it was also found that continuous increases in the maximum and minimum temperatures would be seen in the eastern, northern and southern regions of Jordan.

Studied the temperature trend in Iran during the 50year period and reported an increase in overnight, daily and 24-hour temperatures. Ghahraman (2006) evaluated the trend of mean annual temperature at 34 synoptic stations in Iran and the results showed there was an 
incremental trend in $34 \%$ of stations, a downward trend in $15 \%$ and $41 \%$ of stations had no significant trend. Tabari et al. (2012) studied the mean air temperature at 29 synoptic stations in Iran for the period 1966-2005 and reported the increasing trend in annual $\mathrm{T}_{\text {mean }}$ was $0.22^{\circ} \mathrm{C}$ per decade. Zarenistanak et al. (2014) showed that temperature may increase between 1.69 to $6.88^{\circ} \mathrm{C}$ by 2100 in the southwestern part of Iran using four simulation models. Tabari and Hosseinzadeh-Talaee (2011) analyzed yearly, seasonal and monthly minimum and the maximum air temperature of arid and semi-arid regions of Iran for the 30-year period and found $\mathrm{T}_{\max }$ and $\mathrm{T}_{\text {min }}$ have increased 0.09 and $0.444^{\circ} \mathrm{C}$ per each decade. Ghasemi (2015) studied the variations of Iran temperature during 1961-2010 and showed a dominating positive trend over most parts of Iran with a slope from 0.09 to $0.38^{\circ} \mathrm{C}$ per decade. He also found $\mathrm{T}_{\min }$ increase with the slope of $0.34^{\circ} \mathrm{C}$ per decade is greater than $\mathrm{T}_{\max }$ with the slope of $0.15^{\circ} \mathrm{C}$ per decade and warming occurs in summer and spring more than fall and winter. In addition, Iran's warm climate regions are warming at a higher rate than cold climate regions. Roshan et al. (2011) indicated $4.41^{\circ} \mathrm{C}$ increase in the mean temperature of Iran by 2100 using simulation of temperature in different parts of Iran. Meanwhile, the largest increase would occur in southern and southeastern parts of Isfahan. Dastorani and Poormohammadi (2016) simulated parameters of temperature, precipitation and evapotranspiration for different regions of Iran and showed the largest increase in temperature occurs in western regions of Iran while the largest increase in evapotranspiration occurs in the central parts of the country. Gandomkar (2011) evaluated the variation of mean annual temperature and precipitation over a 46year period in Zayandehrud river basin and showed that no significant increase is observed in the temperature of the whole basin but there was a significant incremental trend in Isfahan metropolis. Azaranfar et al. (2009) investigated the variation of temperature and precipitation in Zayandehrud river basin and their results showed the temperature will rise over the period 20102039. Ataei et al. (2013) studied the average monthly temperature in Isfahan province using 16 stations during a 15-year statistical period and showed an increasing trend in the temperature in $50 \%$ of the basin during the months of June, October, July, November, August and December. Yazdani et al. (2011) analyzed the variation of precipitation and mean annual temperature and precipitation at 6 stations in Zayandehrud river basin during the 40 year period and showed a dominating positive temperature trend in most stations. There are several studies on the impact of temperature rise resulting from climate change on consumption and resources including Booij et al. (2011) forecasted discharges of the Nile River based on the current situation and various scenarios including climate change and simulated future water resources management using RIBASIM model for different points of consumption. Also, the results of this study showed that the impact of climate change on temperature, precipitation and evapotranspiration will significantly change the river flow in the future. Tabari and Marofi (2011) studied the annual, seasonal and monthly reference evapotranspiration in western Iran for the period 1966-2005 and showed that the main reason for the increasing trend in reference evapotranspiration was an increase in temperature. According to studies such as Stewart et al. (2004) and Christensen et al. (2004), it is predicted warming in the mountainous parts of western America led to increasing the ratio of rain to snow, reducing snowpack and the earlier melting of snow, increasing evaporation and transpiration in the hot summer months and reducing the annual surface flow. Study on Murray-Darling basin in Australia has shown variations in precipitation cannot singly justify a reduction in surface flow. The study also indicated a $1{ }^{\circ} \mathrm{C}$ increase in the temperature without any change in precipitation has resulted in a $15 \%$ reduction in the annual surface flow (Cai and Cowan, 2008). Many studies have showed the critical role of increasing temperature in the reduction of surface runoff: Woodhouse et al. (2016) evaluated in an experimental study the effect of rainfall, temperature and antecedent soil moisture in the Colorado river basin and found although each parameter of precipitation, temperature and soil moisture can have a different effect on the reduction of surface flow but, recent drought has spread due to warmer temperatures which exacerbate the effects of reduced rainfall. Gleick (1987a; 1987b) used a water balance model for the Sacramento basin and showed that temperature variations are effective on the seasonal distribution of runoff and soil moisture. Zareian et al. (2015) simulated trend in temperature and evapotranspiration variations in the Zayandehrud river basin for the 30-year period (2015-2044) and showed the average temperature will increase 0.63 to $1.13^{\circ} \mathrm{C}$ in the east of the basin in the future and summer has the maximum temperature rise in this area. Also, the results showed that evapotranspiration increases by 3.1 to $4.8 \%$ due to temperature rise which leads to the imbalance of Agricultural water supplying the eastern part of the basin. In a study conducted in upstream of Zayandehrud river basin, the results have shown discharge into the river dam will be reduced by 18.4 in the summer and spring due to increasing the annual temperature of $1.3^{\circ} \mathrm{C}$ and decreasing precipitation by 5.9\% until 2040 (Ahmadi et al. (2015)). Predicted that the amount of Sheshpir river (one of subbasin of Persian Gulf) flow will decrease by $39 \%$ until 2040 because of rising temperature and reducing rainfall. Showed the relationship between temperature variations, annual precipitation and groundwater (wells) hydrograph fluctuations in Upper Carbonate Aquifer near Winnipeg, Canada. Rosenberg et al. (1999) analyzed the impact of climate change on groundwater recharge in Ogallala aquifer in the United States and understood aquifer recharge would decline more than $7 \%$ using simulation models and increasing temperature parameters and $\mathrm{CO}_{2}$ concentration. McCallum (2010) studied sensitivity 
analysis of climate parameters using a soil-vegetationatmosphere-transfer model to determine the importance of each climate parameters in aquifer recharge for 3 points of Australia and found that increases in temperature and changes in rainfall intensity would lead to a significant change in the aquifer feeding. According to the IPCC predictions, rising temperature and decline in precipitation in the U.S. Southwest play a decisive role in reducing aquifer recharge. Even without any changes in rainfall, higher temperatures lead to increase evaporation and reduce the potential for aquifer feeding. Increasing the temperature during the growing season, even if rainfall does not change, causes a decrease in crop production due to more water stress and evapotranspiration under water-limited conditions (Chen et al., 2010); Schlenker and Lobell, 2010. Chowdhury and Al-Zahrani, 2015) showed a $1^{\circ} \mathrm{C}$ increase in temperature could increase water demand by $2.9 \%$ in $\mathrm{Al}-$ Jouf region. They also found an increase in water demand is mainly because of rising temperature while rainfall changes have little effect. Gohari et al. (2013) studied climate change impacts on crop production in Zayandehrud river basin and showed that rising temperature and decreased rainfall result in increased water demand.

There is so little research done on temperature analysis in Zayandehrud basin that these studies are mainly limited to the average temperature in annual scale. Although, analyzing the average temperature is a useful indicator in assessing variations but, understanding some variations may require the other temperature variables. Whereas the mean temperature variations are the result of changes in Tmax, Tmin or both of them So, the other thermometric variables are considered by researchers including Maximum temperature and minimum temperature. There has been little research conducted on the climate change impact on water resources and consumption in some parts of the basin (upstream-surface water, the eastern part of the basin-evapotranspiration) but, there are no studies identifying the possible effects of temperature rising on resources and consumptions of different areas of the basin. This study has attempted to identify variation trends of the parameters such as overnight, daily and average temperatures in the climatic zones of Zayandehrud river basin and then according to the potentials of each area, the possible effects of rising temperatures on water resources and consumption of these areas will be introduced.

\section{Data and Methods}

\section{Data}

\section{Zayanderoud River Basin}

Zayandehrud river basin is one of the most strategic catchment in central Iran with a total area of over 41,000 square kilometers and a population of over 5.3 million people (Fig. 2). Zayandehrud river is originated from the height of about $3900 \mathrm{~m}$ above sea level and after crossing agricultural lands of the basin and through Isfahan city, finally will reach the Gavkhooni wetland at the lowest point of the basin with a height of $1,400 \mathrm{~m}$ above sea level in the eastern basin. The only permanent river is in central Iran which plays a decisive and vital role to meet industrial, agriculture and domestic needs. Meanwhile, the total basin requirements are about 2250 million cubic meters per year that are supplied by Zayandehrud dam in the basin upstream, the major need is related to agricultural activities (Fig. 1). The basin's water resources are reduced during recent years and has led to water stress, as many agricultural lands were converted into barren lands and Gavkhooni wetland at the end of the basin is often dry (Safavi et al., 2016; Yazdanpanah et al., 2016).

\section{The Climatic Zones of Zayandehrud River Basin}

In terms of topography, this basin has two quite distinct parts. 1: Mountainous areas in the west and southwest of the basin 2: The vast plain that is located in the middle and eastern basin and leads to Gavkhooni wetland. Topographic features of the basin have led to Climate variations in different parts of the basin as the basin can be divided into five different climatic zones (Fig. 3) (Montazeri and Karimpur, 2011). These climatic zones include 1-Cold and rainy climate of FreydanKoohrang (FK) in a western basin which includes areas with high rainfall and cold and covers 12 percent of the area. The high altitude of the area causes rainfall in the form of snow. 2- Semi cold and low rainfall climate of Najafabad-Dehaq (ND) in the middle of the basin that covers $17 \%$ of the area. The density of altitudes in this zone is less and decrease from west to east with a relatively high slope as the topography is shown in the form of plain and mountain. 3- Temperate and relatively dry climate of Mourchekhort-Meimeh (MM) in the northern basin that covers 12 percent of the area. The majority of the area is made up of flat and smooth lands. 4- Semi-cold and low rainfall climate of ShahrezaEzadkhast (SE) in the southern basin that is included $23 \%$ of the basin area. There is a relatively wide plain in the East and West Sides of this mountainous area and it's middle part. 5- Temperate, very dry and low rainfall climate of Esfahan-Gavkhooni (EG) in the eastern basin which is included $36 \%$ of the basin area. The Northwest of this area is a fertile plain but after advancing towards the eastern and southern sides, lowlands and sandy hills and sabulous are seen. Annual mean climate parameters of the different zones of Zayandehrud river basin is presented in Table 1. EG area is the largest and most populous area $(62 \%$ of the basin's population) among different zones of the basin. Also, the highest urban population belongs to this area which is included Esfahan metropolis. In 
addition, the largest Agricultural land of the basin is located in this area that is mainly irrigated by Zayandehrud dam. The maximum water demand is related to this area due to containing considerable population and agricultural lands (Fig. 4). The lowest population (1.4\%) and water use among different areas belong to $\mathrm{MM}$ area while the most available water resources to use is related to $\mathrm{FK}$ area (Fig. 4). Surface water resources in this area (by storing in Zayandehrud dam) supply more than $70 \%$ of the basin water requirement. MM area has the lowest available water resources including only groundwater resources and there are not any controlled surface water resources (Kouhestani et al., 2016).

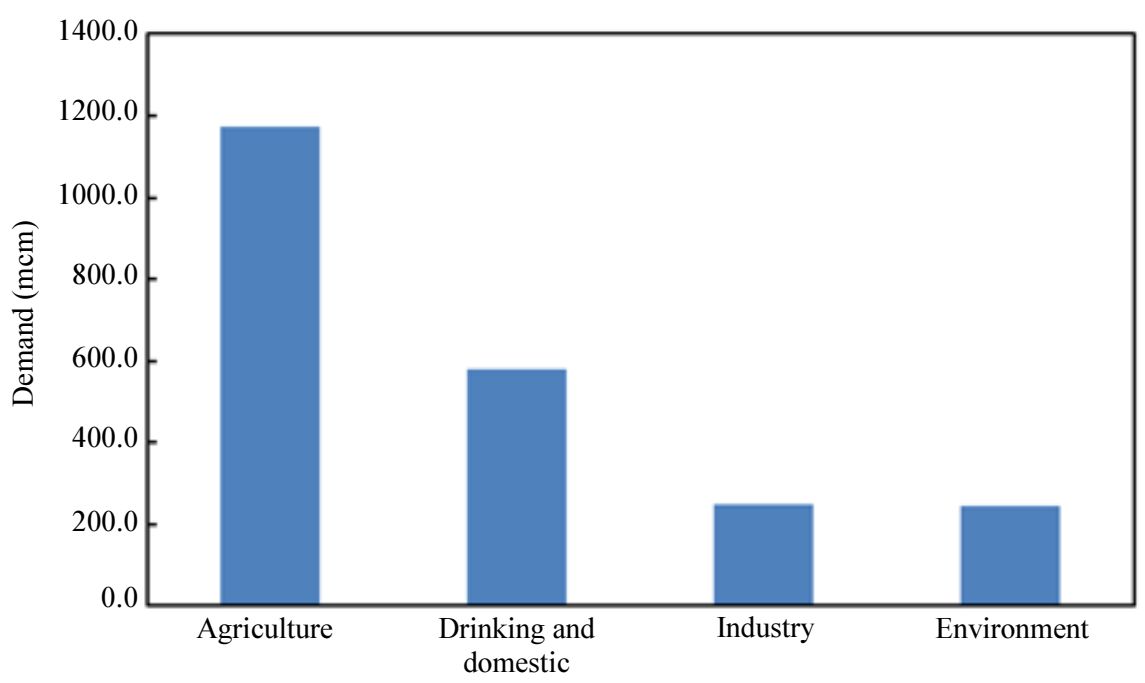

Fig. 1: The total requirements of Zayanderoud basin (Safavi et al., 2016)

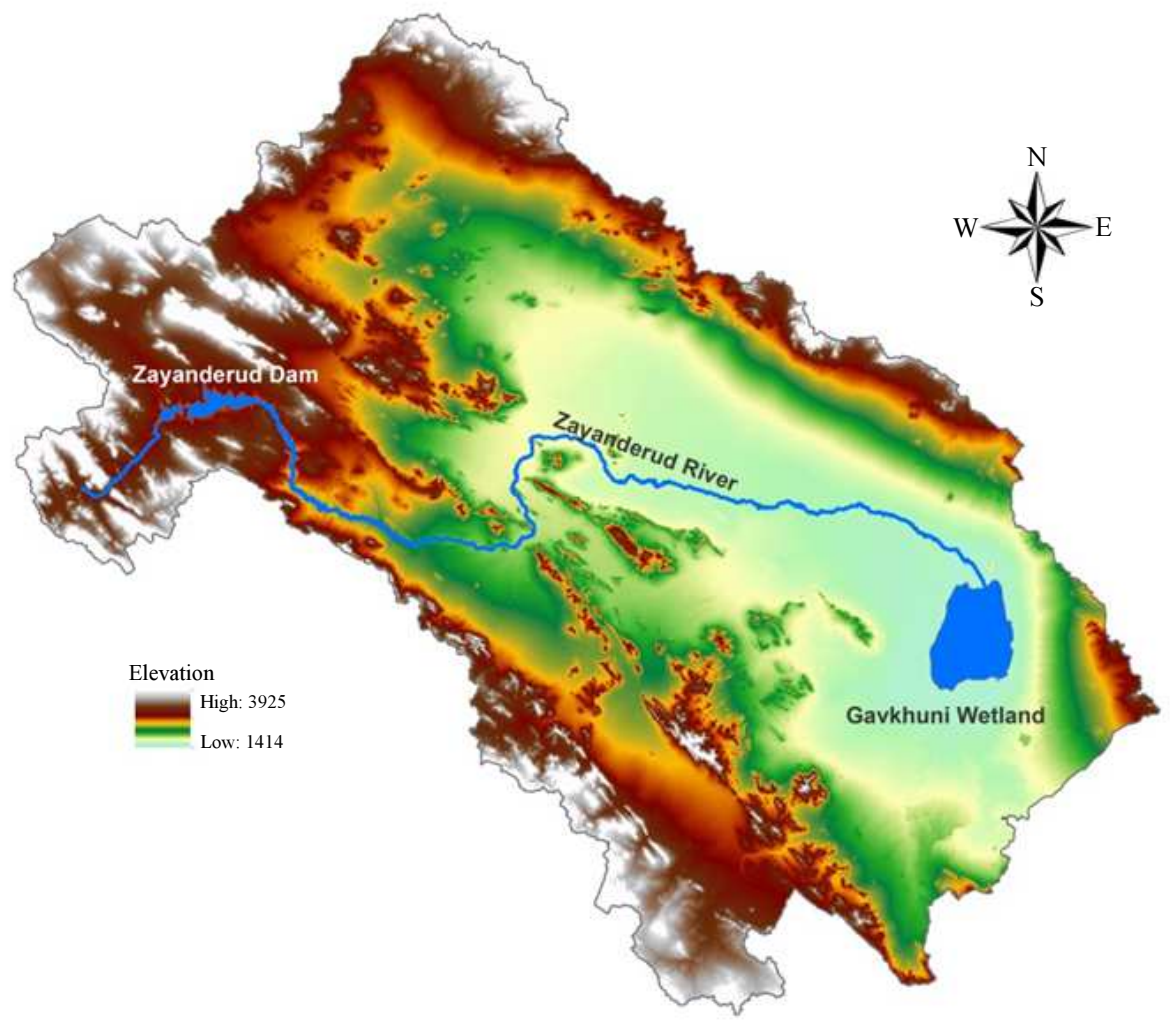

Fig. 2: Zayandehrud river basin 


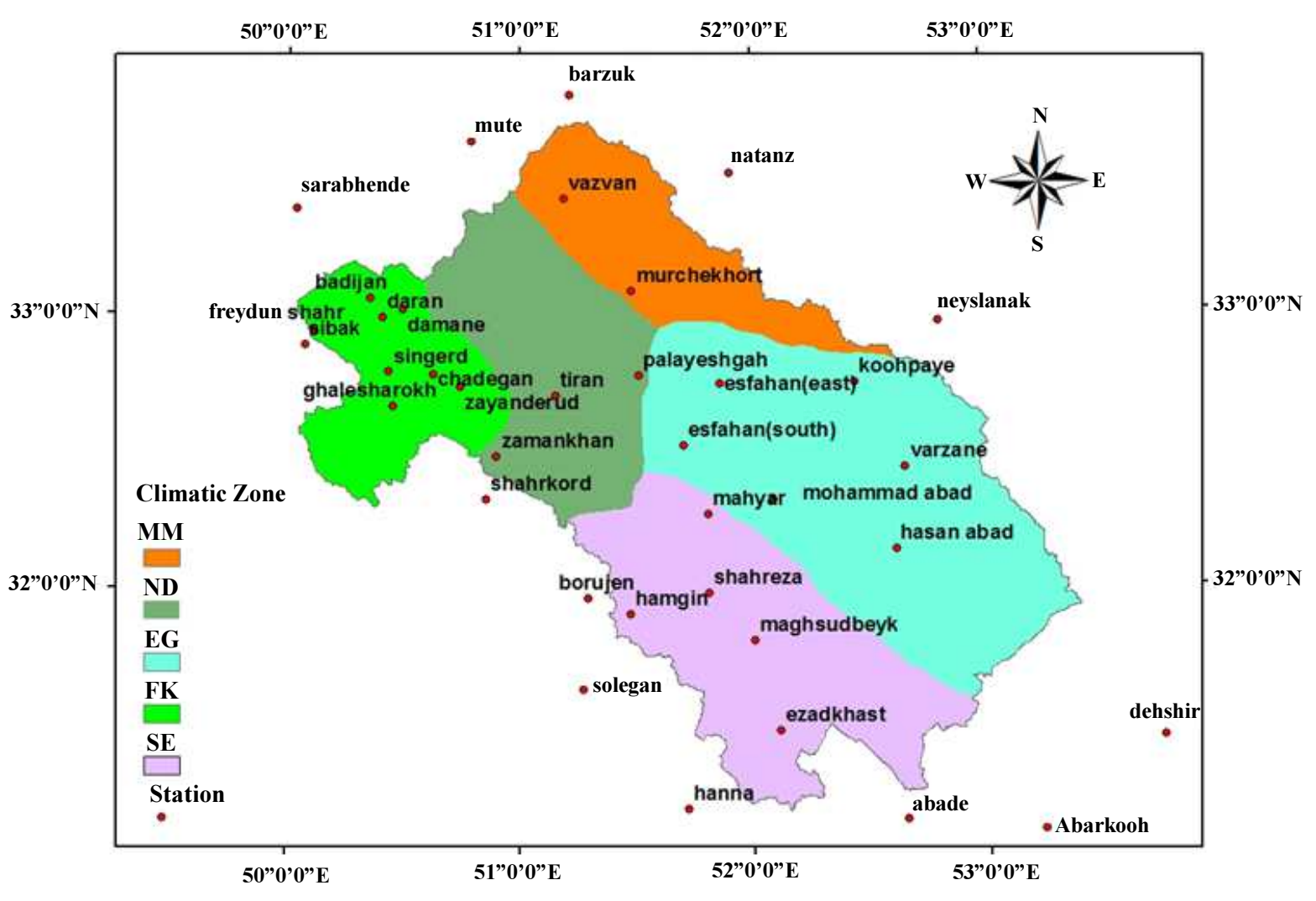

Fig. 3: Climatic zones of Zayandehrud river basin and the location of weather stations

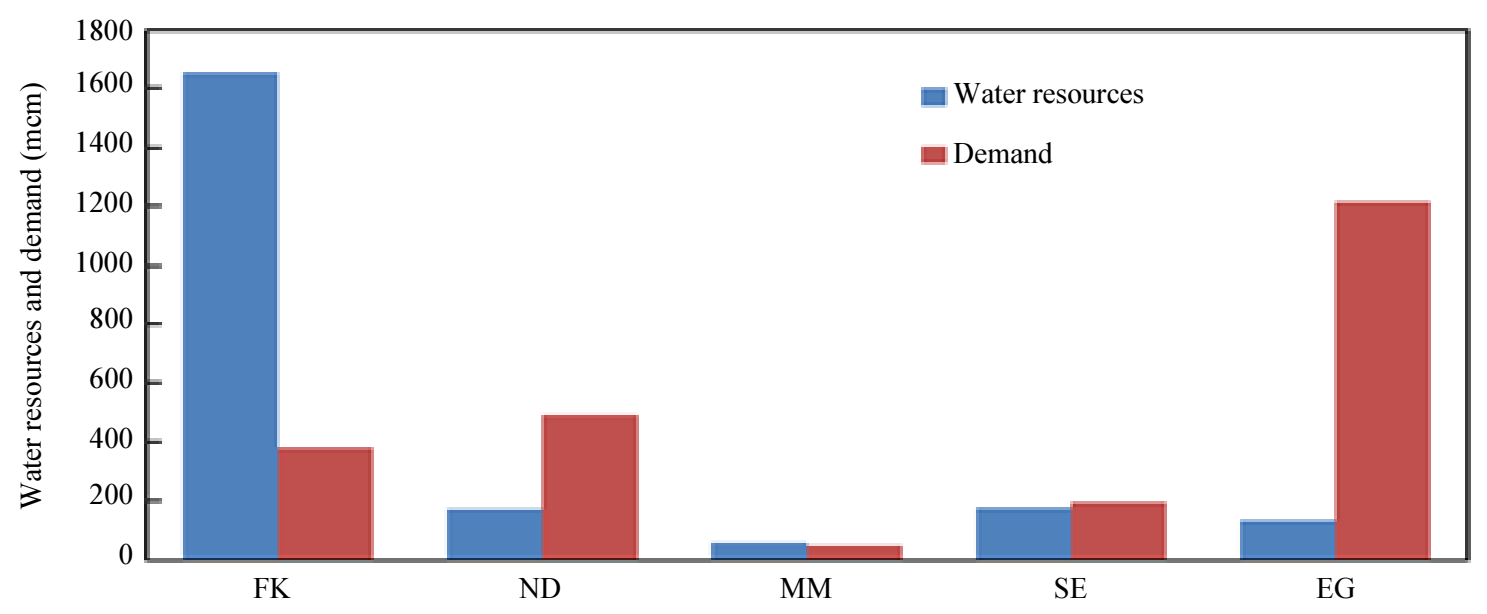

Fig. 4: Water resources and water requirements in different zones of the basin (Kouhestani et al., 2016)

Table 1: The annual mean climate characteristics of different zones in the Zayandehrud river basin (Kouhestani et al., 2016)

\begin{tabular}{lrrrrr}
\hline Variable & FK & ND & MM & SE & EG \\
\hline $\mathrm{T}_{\min }\left({ }^{\circ} \mathrm{C}\right)$ & 4.6 & 6.8 & 8.9 & 5.7 & 7.5 \\
$\mathrm{~T}_{\max }\left({ }^{\circ} \mathrm{C}\right)$ & 19.0 & 21.9 & 24.3 & 21.4 & 23.8 \\
$\mathrm{~T}_{\text {mean }}\left({ }^{\circ} \mathrm{C}\right)$ & 11.9 & 14.5 & 16.9 & 13.7 & 15.9 \\
Rainfall (mm) & 762.9 & 295.3 & 165.4 & 134.2 & 86.4 \\
Relative Humidity (percent) & 44.6 & 42.7 & 40.2 & 37.7 & 36.9 \\
\hline
\end{tabular}


Figure 1 shows Total water demand for four different categories that the most important of them is agriculture which is almost $1200 \mathrm{mcm}$ and both of them (Industry and Environment) are lowest Demand which almost are $200 \mathrm{mcm}$ (million cubic meters)

\section{Climatic Data}

In this study temperature data of the basin and its surroundings were studied (Fig. 3). Monthly data until 2010 is received from meteorological organization and ministry of energy and was extracted by averaging seasonal data. Different seasons in the basin are defined as below:

- $\quad$ Spring = March, April, May

- $\quad$ Summer = June, July, August

- $\quad$ Fall $=$ September, October, November

- $\quad$ Winter $=$ December, January, February

The location of stations is shown in Fig. 3. These stations do not have the same record length. However, for maximum coverage in different parts of the basin and more appropriate temperature analysis in different zones of all stations is used in this study (Romero-Higareda et al., 2014). Three temperature variables were used to analyze the temperature trend in the basin:

1. The minimum temperature or overnight temperature $\left(\mathrm{T}_{\min }\right)$

2. The average temperature $\left(\mathrm{T}_{\text {mean }}\right)$

3. The Maximum temperature or daily temperature $\left(\mathrm{T}_{\max }\right)$

\section{Methods}

\section{Mann-Kendall (MK) Trend Test}

MK tests are used for a more meaningful study in hydro meteorological time series (Islam, 2015) which the significance of the temperature trend has been investigated in the study area stations. The original model of this test was first developed by MAN (Mann, 1945) and then Kendall extracted and presented the statistical distribution of the test (Kendall, 1975)

This method is a non-parametric method and the assumption of normal data is not necessary. Moreover, this method is not sensitive to the sudden failure of non-homogeneous time series (Jaagus, 2006; Mann, 1945). The MK test relations are as follows (Kouhestani et al., 2016):

$$
S=\sum_{i=1}^{n-1} \sum_{j=i+1}^{n} \operatorname{sgn}\left(x_{j}-x_{i}\right)
$$

In the Equation (1), $N$ : The total number of data and $x_{i}$ and $x_{j}$ are the value of $i$ and $j$ data in time series $(j>i)$. Function $\operatorname{sgn}\left(x_{j}-x_{i}\right)$ is defined as follows (Kouhestani et al., 2016):

$\operatorname{sgn}\left(x_{j}-x_{i}\right)=\left\{\begin{array}{l}+1, \text { if }\left(x_{j}-x_{i}\right)>0 \\ 0, \text { if }\left(x_{j}-x_{i}\right)=0 \\ -1, \text { if }\left(x_{j}-x_{i}\right)<0\end{array}\right.$

The variance is also calculated from the following equation (Kouhestani et al., 2016):

$V(S)=\frac{n(n-1)(2 n+5)-\sum_{k=1}^{m} t_{k}\left(t_{k}-1\right)\left(2 t_{k}+5\right)}{18}$

In Equation (3), $n$ is the number of data points, $m$ is the number of tied groups and $t_{k}$ denotes the number of ties of extent $k$. A tied group is a set of sample data having the same value. In cases where the sample size $n>10$, the standard normal test statistic $Z_{S}$ is computed using Equation (4) (Kouhestani et al., 2016):

$Z_{S}=\left\{\begin{array}{l}\frac{S-1}{\sqrt{V(S)}}, \text { if } S>0 \\ 0, \text { if } S=0 \\ \frac{S+1}{\sqrt{V(S)}}, \text { if } S<0\end{array}\right.$

MK test is used to detect trend, if a trend in temperature time series is statistically significant at the $\alpha$ $=0.05$ level (or 95\% confidence interval). The null hypothesis of no trend is rejected at the $5 \%$ significance level if $|Z|>1.96$ (Islam, 2015).

\section{Sen-Slope (SS)}

The MK test does not provide an estimate of the magnitude of the trend. For this purpose, in this study we evaluated the magnitude of the trend by applying the $Q$ Sen's slope estimator using steps below (Sen, (1968)):

- The interval between time series data points should be equally spaced

- Data should be sorted in ascending order according to time, then the following formula is applied to calculate Sen's slope $\left(Q_{k}\right)$ (Kouhestani et al., 2016.):

$Q_{k}=\frac{x_{j}-x_{i}}{j-i}$ for $k=1,2, \ldots ., N$

In Equation (5), $x_{j}$ and $x_{i}$ are the data values at times $j$ and $i(j>i)$, respectively. 
In the Sen's vector matrix members of size $=\frac{n(n-1)}{2}$, where $n$ is the number of time periods. The total $N$ values of $Q_{k}$ are ranked from smallest to largest and the median of slope or Sen's slope estimator is computed as (Kouhestani et al., 2016.):

$Q_{\text {med }}= \begin{cases}Q_{\left[N+\frac{1}{2}\right]} & \text { if } N \text { is odd } \\ \frac{Q_{\left[\frac{N}{2}\right]}+Q_{\left[N+\frac{2}{2}\right]}}{2} & \text { if } N \text { is even }\end{cases}$

$Q_{\text {med }}$ sign reflects data trend direction, while its value indicates the steepness of the trend.

\section{Serial Correlation Effect}

In order to remove the influence of the serial correlation the pre-whitened time series before applying $Q$ Sen's slope estimator and MK test is used. In this study, the first serial correlation coefficient $\left(r_{1}\right)$ is calculated for time series $\left(x_{1}, x_{2}, x_{3}, \ldots x_{n}\right)$ with lag-1. It can be computed by (Kouhestani et al., 2016):

$r_{1}=\frac{\frac{1}{n-1} \sum_{i=1}^{n-1}\left(x_{i}-E\left(x_{i}\right)\right) \cdot\left(x_{i+1}-E\left(x_{i}\right)\right)}{\frac{1}{n} \sum_{i=1}^{n}\left(x_{i}-E\left(x_{i}\right)\right)^{2}}$

$E\left(x_{i}\right)=\frac{1}{n} \sum_{i=1}^{n}\left(x_{i}\right)$

where, $n$ is the number of observations and $E\left(x_{i}\right)$, the mean of sample data. The following equation for testing the time series data sets of serial correlation will be used (Kouhestani et al., 2016): $\frac{-1-1.645 \sqrt{n}-2}{n-1}<r_{1}<\frac{-1+1.645 \sqrt{n}-2}{n-1}$

If $r_{1}$ drops inside the above interval, the time series data set are considered as independent observations. Where $r_{1}$ is outside the above interval, the data has a serial correlation. If time series data sets contain independent, the MK test and the SS can be used to the original time series. Otherwise, they will be used on pre-whitening time series $\left(x_{2}-r_{1} x_{3}, x_{3}-r_{1} x_{2} \ldots \ldots, x_{\mathrm{n}}-\mathrm{r}_{1} x_{n-1}\right)$ (Gocic and Trajkovic, 2013; Sayemuzzaman et al., 2014; Islam, 2015).

\section{Regional Analysis}

In this study, three methods have been investigated for Trend analysis at each basin climatic zone. These methods include:

1. IDW interpolation technique in ArcGIS framework

2. Multiple linear regression model with physiographic parameters including latitude, latitude and elevation

3. Direct use of the average values of the stations in each climatic zone

In methods 1 and 2, spatial distribution map of trend slope of $T_{\max }, T_{\text {mean }}, T_{\min }$ is provided in the entire Zayandehrud basin and the Trend values in each climatic zone are extracted from these maps. In method 3, nearby stations and inside of each climatic zone are detected and the mean values of trend slope of these stations are considered as the moderate slope of the zone. All stations were used in methods 1 and 2. However, in order to calculate the mean slope of temperature in each climate zone (in method 3), different stations were used according to Table 2 and trend slope of temperature is calculated throughout the basin using all the stations.

Table 2: Stations used to calculate the average slope of the trend in each climate zone (method 3)

\begin{tabular}{lllll}
\hline FK & ND & MM & SE & EG \\
\hline Shahrkord & Shahrkord & Vazvan & Abade & Abarkooh \\
Zamankhan & Zamankhan & Mute & Hanna & Dehshir \\
Ghalesharokh & Tiran & Natanz & Abarkooh & Mahyar \\
Zayandehrud & Palayeshgah & Barzuk & Solegan & Mohamadabad \\
Chadegan & Vazvan & Neysianak & Borujen & Hasanabad \\
Singerd & Murchekhort & Murchekhort & Hamgin & Varzane \\
Damane & Esfahan(south) & Palayeshgah & Ezadkhast & Isfahan(South) \\
Sibak & Mute & Esfahan(east) & Shahreza & Koohpaye \\
Daran & Zayandehrud & Koohpaye & Maghsudbeyk & Neysianak \\
Badijan & Chadegan & & Isfahan(South) & Isfahan(East) \\
Fereydunshahr & Damane & & Mahyar & Palayeshgah \\
Sarabhende & & & Mohamadabad & \\
& & & Hasanabad & \\
\hline
\end{tabular}




\section{Results and Discussion}

\section{Temperature Trend at the Stations}

Table 3 shows the results of the slope of the trend line calculations using Q Sen's Slop parameter for $\mathrm{T}_{\text {min }}, \mathrm{T}_{\text {mean }}$ and $\mathrm{T}_{\max }$ in different seasons for each station. In this table, the negative values represent the slope of the trend, the positive values of the incremental slope and the zero values indicate the absence of a trend. At the bottom of the table, the numbers of stations that have increased, a decreasing and no trend are counted and presented for each temperature parameter in different seasons from the top of the table. Table 4 shows the results of the Mann-Kendall calculations to determine significantly the trend of temperature. In this table, the MannKendall statistic is shown at each station for $\mathrm{T}_{\max }$, $\mathrm{T}_{\text {mean }}, \mathrm{T}_{\min }$ at different seasons of the year. Each parameter at each station which is significant at least at $p<0.05$, is shown as boid and the number of stations having significant incremental or decreasing trend has been counted and presented at the bottom of the table.

Table 3: The values of Q Sen's Slop (temperature trend slope) and the number of stations with increasing, decreasing and without trend

\begin{tabular}{|c|c|c|c|c|c|c|c|c|c|c|c|c|c|c|}
\hline \multirow[b]{3}{*}{ Row } & \multirow[b]{3}{*}{ Station } & \multirow{3}{*}{$\begin{array}{l}\text { Year } \\
\text { of data }\end{array}$} & \multicolumn{12}{|c|}{ Trend slope $\left({ }^{\circ} \mathrm{C} /\right.$ year $)$} \\
\hline & & & \multicolumn{3}{|l|}{ Spring } & \multicolumn{3}{|c|}{ Summer } & \multicolumn{3}{|l|}{ Fall } & \multicolumn{3}{|l|}{ Winter } \\
\hline & & & $\mathrm{T}_{\min }$ & $\mathrm{T}_{\text {mean }}$ & $\mathrm{T}_{\max }$ & $\mathrm{T}_{\min }$ & $\mathrm{T}_{\text {mean }}$ & $\mathrm{T}_{\max }$ & $\mathrm{T}_{\min }$ & $\mathrm{T}_{\text {mean }}$ & $\mathrm{T}_{\max }$ & $\mathrm{T}_{\min }$ & $\mathrm{T}_{\text {mean }}$ & $\mathrm{T}_{\max }$ \\
\hline 1 & Abade & $1977-2010$ & 0.018 & 0.015 & 0.006 & 0.016 & 0.013 & -0.014 & -0.001 & 0.005 & 0.010 & -0.011 & -0.006 & -0.004 \\
\hline 2 & Abarkooh & $1997-2010$ & 0.003 & -0.001 & -0.023 & 0.010 & 0.006 & -0.016 & 0.026 & 0.022 & 0.036 & 0.002 & 0.003 & 0.001 \\
\hline 3 & Badijan & $1965-2010$ & 0.022 & 0.028 & 0.007 & 0.015 & 0.009 & 0.012 & -0.032 & -0.028 & -0.012 & -0.024 & -0.027 & -0.006 \\
\hline 4 & Barzuk & $1998-2010$ & 0.018 & 0.000 & -0.006 & 0.006 & 0.008 & 0.020 & 0.036 & 0.027 & 0.027 & -0.050 & -0.032 & -0.019 \\
\hline 5 & Borujen & $1988-2010$ & 0.009 & 0.015 & 0.016 & 0.012 & 0.012 & 0.024 & -0.015 & -0.010 & -0.007 & -0.026 & -0.023 & -0.024 \\
\hline 6 & Chadegan & $1978-2010$ & 0.025 & 0.030 & 0.009 & 0.030 & 0.013 & 0.011 & -0.019 & -0.010 & 0.008 & -0.033 & -0.027 & -0.004 \\
\hline 7 & Damane & $1965-2010$ & 0.005 & 0.015 & 0.023 & 0.019 & 0.009 & 0.019 & -0.010 & -0.002 & 0.006 & -0.042 & -0.030 & -0.007 \\
\hline 8 & Daran & $1989-2010$ & 0.008 & 0.014 & 0.017 & 0.008 & 0.011 & 0.014 & 0.009 & 0.002 & -0.015 & 0.008 & 0.003 & -0.009 \\
\hline 9 & Dehshir & $1993-2010$ & 0.000 & -0.002 & -0.012 & 0.010 & 0.011 & -0.007 & 0.019 & 0.020 & 0.033 & -0.002 & -0.005 & -0.021 \\
\hline 10 & Isfahan(east) & $1976-2010$ & 0.018 & 0.027 & 0.011 & 0.015 & 0.018 & 0.011 & 0.000 & 0.002 & 0.002 & -0.021 & -0.016 & -0.004 \\
\hline 11 & Isfahan(south) & $1951-2010$ & 0.019 & 0.024 & 0.014 & 0.011 & 0.016 & 0.010 & 0.014 & 0.020 & 0.009 & 0.011 & 0.006 & 0.008 \\
\hline 12 & Ezadkhast & $1976-2010$ & 0.009 & -0.007 & -0.027 & 0.034 & 0.029 & 0.028 & 0.026 & 0.019 & 0.038 & -0.036 & -0.020 & -0.022 \\
\hline 13 & Fereydunshahr & $1978-2010$ & 0.004 & 0.005 & -0.002 & 0.020 & 0.015 & 0.015 & 0.025 & 0.018 & -0.001 & 0.011 & 0.000 & -0.020 \\
\hline 14 & Ghalesharokh & $1967-2010$ & 0.011 & 0.015 & -0.035 & 0.014 & 0.014 & 0.017 & -0.020 & -0.001 & 0.032 & -0.059 & -0.052 & -0.032 \\
\hline 15 & Hamgin & $1966-2010$ & 0.027 & -0.027 & -0.048 & 0.021 & 0.015 & 0.019 & -0.024 & -0.010 & 0.018 & -0.017 & -0.014 & 0.013 \\
\hline 16 & Hanna & $1982-2010$ & 0.053 & 0.030 & -0.043 & -0.126 & -0.061 & 0.043 & 0.045 & 0.035 & 0.029 & 0.123 & 0.076 & -0.050 \\
\hline 17 & Hasanabad & $1998-2010$ & 0.048 & 0.025 & 0.000 & 0.031 & 0.031 & 0.008 & 0.036 & 0.025 & 0.024 & -0.019 & -0.005 & -0.008 \\
\hline 18 & Koohpaye & $1974-2010$ & -0.024 & -0.024 & -0.019 & 0.012 & 0.018 & 0.033 & 0.007 & 0.016 & 0.039 & -0.030 & -0.029 & -0.013 \\
\hline 19 & Maghsudbeyk & $1968-2010$ & 0.021 & 0.000 & -0.021 & 0.032 & 0.025 & 0.007 & 0.025 & 0.032 & 0.033 & -0.022 & -0.017 & -0.004 \\
\hline 20 & Mahyar & $1968-2010$ & 0.020 & 0.005 & -0.012 & 0.023 & 0.024 & 0.012 & 0.023 & 0.031 & 0.039 & 0.005 & 0.003 & -0.004 \\
\hline 21 & Mohamadabad & $1993-2010$ & 0.015 & 0.002 & -0.024 & 0.013 & 0.020 & 0.018 & 0.015 & 0.019 & 0.029 & -0.018 & -0.027 & -0.013 \\
\hline 22 & Murchekhort & $1971-2010$ & 0.017 & 0.009 & -0.013 & 0.029 & 0.025 & 0.024 & 0.022 & 0.031 & 0.047 & -0.029 & -0.019 & -0.016 \\
\hline 23 & Mute & $1976-2010$ & 0.021 & -0.003 & -0.010 & 0.015 & 0.012 & 0.021 & 0.018 & 0.026 & 0.044 & -0.043 & -0.031 & -0.023 \\
\hline 24 & Natanz & $1992-2010$ & 0.037 & 0.028 & 0.025 & 0.026 & 0.022 & 0.021 & 0.022 & 0.022 & -0.003 & 0.011 & -0.007 & -0.019 \\
\hline 25 & Neysianak & $1971-2010$ & 0.023 & 0.011 & -0.029 & 0.039 & 0.017 & 0.029 & 0.008 & 0.019 & 0.032 & -0.021 & -0.017 & -0.012 \\
\hline 26 & Palayeshgah & $1986-2010$ & 0.025 & 0.020 & 0.005 & 0.007 & 0.007 & 0.000 & 0.026 & 0.024 & -0.005 & 0.031 & 0.016 & -0.006 \\
\hline 27 & Sarabhende & $1968-2010$ & 0.005 & -0.011 & -0.036 & 0.024 & 0.025 & 0.029 & 0.030 & 0.037 & 0.032 & 0.011 & 0.012 & 0.003 \\
\hline 28 & Shahreza & $1973-2010$ & 0.015 & 0.016 & 0.001 & 0.015 & 0.012 & -0.001 & 0.005 & 0.005 & 0.002 & -0.008 & -0.006 & -0.014 \\
\hline 29 & Shahrkord & $1955-2010$ & -0.007 & -0.006 & -0.006 & -0.002 & -0.007 & -0.011 & -0.015 & -0.014 & -0.011 & -0.024 & -0.008 & 0.000 \\
\hline 30 & Sibak & $1995-2010$ & 0.005 & 0.021 & 0.035 & 0.018 & 0.012 & -0.013 & 0.007 & -0.010 & -0.022 & -0.028 & -0.019 & 0.010 \\
\hline 31 & Singerd & $1976-2010$ & 0.001 & 0.012 & -0.001 & 0.002 & 0.005 & 0.008 & 0.000 & -0.010 & 0.008 & -0.001 & -0.007 & -0.017 \\
\hline 32 & Solegan & $1980-2010$ & -0.015 & -0.020 & -0.025 & 0.013 & 0.009 & 0.013 & 0.014 & 0.019 & 0.031 & -0.041 & -0.037 & -0.027 \\
\hline 33 & Tiran & $1972-2010$ & -0.028 & -0.019 & -0.011 & -0.010 & -0.002 & 0.009 & 0.027 & 0.027 & 0.040 & 0.057 & 0.057 & 0.040 \\
\hline 34 & Varzane & $1961-2010$ & 0.050 & -0.006 & 0.012 & 0.049 & -0.007 & 0.008 & 0.036 & 0.015 & 0.008 & -0.004 & 0.020 & 0.004 \\
\hline 35 & Vazvan & $1971-2010$ & 0.011 & -0.015 & -0.026 & 0.139 & 0.061 & 0.008 & 0.007 & 0.010 & 0.018 & -0.036 & -0.027 & -0.045 \\
\hline 36 & Zamankhan & $1958-2010$ & 0.013 & -0.006 & -0.031 & 0.013 & -0.007 & -0.014 & 0.010 & 0.015 & 0.020 & 0.029 & 0.020 & 0.019 \\
\hline 37 & Zayandehrud & $1967-2010$ & -0.013 & -0.016 & -0.026 & 0.006 & 0.007 & 0.009 & 0.021 & 0.028 & 0.039 & -0.001 & -0.005 & -0.023 \\
\hline \multicolumn{15}{|c|}{$\begin{array}{l}\text { The number of stations with increasing, decreasing and without trend } \\
\text { Variable (number) }\end{array}$} \\
\hline \multicolumn{3}{|c|}{$\begin{array}{l}\text { The number of stations with } \\
\text { decreasing trend }\end{array}$} & 5 & 14 & 24 & 3 & 5 & 7 & 8 & 9 & 8 & 27 & 26 & 28 \\
\hline \multicolumn{3}{|c|}{ The number of stations without trend } & 1 & 2 & 1 & 0 & 0 & 1 & 2 & 0 & 0 & 0 & 1 & 1 \\
\hline \multicolumn{3}{|c|}{$\begin{array}{l}\text { The number of stations with } \\
\text { increasing trend }\end{array}$} & 31 & 21 & 12 & 34 & 32 & 29 & 27 & 28 & 29 & 10 & 10 & 8 \\
\hline
\end{tabular}


Table 4: The Mann-Kendall test statistic and the number of stations having significant trend (Bold numbers represent significance of temperature trend at each station)

\begin{tabular}{|c|c|c|c|c|c|c|c|c|c|c|c|c|c|c|}
\hline \multirow[b]{3}{*}{ Row } & \multirow[b]{3}{*}{ Station } & \multirow[b]{3}{*}{$\begin{array}{l}\text { Year } \\
\text { of data }\end{array}$} & \multicolumn{12}{|c|}{ Test statistics Mann-Kendal } \\
\hline & & & \multicolumn{3}{|l|}{ Spring } & \multicolumn{3}{|c|}{ Summer } & \multicolumn{3}{|l|}{ Fall } & \multicolumn{3}{|l|}{ Winter } \\
\hline & & & $\mathrm{T}_{\min }$ & $\mathrm{T}_{\text {mean }}$ & $\mathrm{T}_{\max }$ & $\mathrm{T}_{\text {min }}$ & $\mathrm{T}_{\text {mean }}$ & $\mathrm{T}_{\max }$ & $\mathrm{T}_{\min }$ & $\mathrm{T}_{\text {mean }}$ & $\mathrm{T}_{\max }$ & $\mathrm{T}_{\min }$ & $\mathrm{T}_{\text {mean }}$ & $\mathrm{T}_{\max }$ \\
\hline 1 & Abade & $1977-2010$ & 2.240 & 1.986 & 0.657 & 2.240 & 1.932 & -1.925 & -0.188 & 0.724 & 1.020 & -1.100 & -0.604 & -0.228 \\
\hline 2 & Abarkooh & $1997-2010$ & 0.295 & -0.080 & -1.905 & 0.805 & 0.631 & -1.704 & 2.308 & 2.455 & 3.005 & 0.134 & 0.134 & 0.080 \\
\hline 3 & Badijan & $1965-2010$ & 2.227 & 2.388 & 0.496 & 1.570 & 1.409 & 1.409 & -3.099 & -2.764 & -1.020 & -1.503 & -1.744 & -0.268 \\
\hline 4 & Barzuk & $1998-2010$ & 1.563 & 0.027 & -0.792 & 0.537 & 0.899 & 2.844 & 3.287 & 3.367 & 3.220 & -2.039 & -1.690 & -1.610 \\
\hline 5 & Borujen & $1988-2010$ & 1.436 & 2.147 & 1.543 & 1.945 & 1.878 & 2.388 & -1.878 & -1.207 & -0.550 & -1.422 & -1.583 & -1.784 \\
\hline 6 & Chadegan & $1978-2010$ & 3.032 & 3.502 & 0.765 & 2.952 & 1.878 & 1.395 & -1.945 & -0.724 & 0.496 & -2.254 & -1.234 & -0.107 \\
\hline 7 & Damane & $1965-2010$ & 0.590 & 1.637 & 1.731 & 1.878 & 0.885 & 2.173 & -0.818 & -0.255 & 0.570 & -2.227 & -1.570 & -0.255 \\
\hline 8 & Daran & $1989-2010$ & 0.939 & 1.610 & 1.905 & 0.765 & 1.060 & 1.637 & 0.859 & 0.067 & -1.140 & 0.335 & 0.121 & -0.483 \\
\hline 9 & Dehshir & $1993-2010$ & -0.013 & -0.188 & -1.087 & 1.006 & 0.953 & -0.953 & 1.838 & 2.442 & 2.844 & -0.201 & -0.456 & -1.717 \\
\hline 10 & Isfahan(East) & $1976-2010$ & 2.952 & 3.381 & 1.053 & 1.798 & 2.509 & 1.584 & 0.121 & 0.309 & 0.121 & -1.932 & -1.610 & -0.335 \\
\hline 11 & Isfahan(South) & $1951-2010$ & 2.381 & 2.925 & 1.757 & 1.409 & 2.200 & 1.315 & 2.039 & 2.992 & 0.886 & 1.127 & 0.631 & 0.537 \\
\hline 12 & Ezadkhast & $1976-2010$ & 1.020 & -0.771 & -2.408 & 2.925 & 2.965 & 2.884 & 2.918 & 2.710 & 3.314 & -2.958 & -1.905 & -1.711 \\
\hline 13 & Fereydunshahr & $1978-2010$ & 0.402 & 0.510 & -0.201 & 1.986 & 1.825 & 1.704 & 2.173 & 1.436 & -0.054 & 0.577 & 0.000 & -0.979 \\
\hline 14 & Ghalesharokh & $1967-2010$ & 2.562 & 1.664 & -2.811 & 2.858 & 1.570 & 1.556 & -3.877 & -0.148 & 2.375 & -3.381 & -2.254 & -1.207 \\
\hline 15 & Hamgin & $1966-2010$ & 2.388 & -3.099 & -3.193 & 1.737 & 1.436 & 1.717 & -2.442 & -1.288 & 1.462 & -1.154 & -1.409 & 0.979 \\
\hline 16 & Hanna & $1982-2010$ & 2.549 & 2.428 & -3.636 & -3.663 & -3.233 & 4.280 & 1.986 & 2.777 & 2.308 & 3.582 & 3.233 & -2.817 \\
\hline 17 & Hasanabad & $1998-2010$ & 4.575 & 3.273 & 0.040 & 3.206 & 3.220 & 1.087 & 2.254 & 2.401 & 2.428 & -1.697 & -0.510 & -0.617 \\
\hline 18 & Koohpaye & $1974-2010$ & -2.107 & -2.462 & -1.449 & 1.422 & 2.187 & 3.180 & & 2.093 & 3.502 & -2.670 & -2.455 & -1.020 \\
\hline 19 & Maghsudbeyk & $1968-2010$ & 3.025 & -0.040 & -1.811 & 2.871 & 2.576 & 0.993 & 3.348 & 3.461 & 2.469 & -1.744 & -1.275 & -0.282 \\
\hline 20 & Mahyar & $1968-2010$ & 1.744 & 0.429 & -0.926 & 2.603 & 2.522 & 1.073 & 2.737 & 2.737 & 2.616 & 0.335 & 0.268 & -0.309 \\
\hline 21 & Mohamadabad & $1993-2010$ & 2.093 & 0.168 & -2.388 & 2.200 & 2.603 & 1.932 & 2.361 & 3.287 & 2.871 & -1.717 & -2.697 & -1.181 \\
\hline 22 & Murchekhort & $1971-2010$ & 1.798 & 0.845 & -0.939 & 2.978 & 2.616 & 2.522 & 3.086 & 3.971 & 4.146 & -2.401 & -1.610 & -0.926 \\
\hline 23 & Mute & $1976-2010$ & 2.818 & -0.335 & -1.087 & 1.811 & 1.395 & 2.375 & 2.750 & 3.703 & 4.011 & -2.952 & -2.012 & -1.476 \\
\hline 24 & Natanz & $1992-2010$ & 3.193 & 2.616 & 1.717 & 2.187 & 2.348 & 2.308 & 2.455 & 3.032 & -0.255 & 0.805 & -0.362 & -1.288 \\
\hline 25 & Neysianak & $1971-2010$ & 3.528 & 1.529 & -2.308 & 3.743 & 2.079 & 3.488 & 1.087 & 2.710 & 3.327 & -1.623 & -1.489 & -0.724 \\
\hline 26 & Palayeshgah & $1986-2010$ & 2.173 & 2.616 & 0.678 & 0.698 & 0.953 & 0.000 & 3.059 & 3.341 & -0.523 & 2.817 & 1.529 & -0.470 \\
\hline 27 & Sarabhende & $1968-2010$ & 0.644 & -0.832 & -2.898 & 1.597 & 2.415 & 2.455 & 2.536 & 3.461 & 2.254 & 0.443 & 0.577 & 0.107 \\
\hline 28 & Shahreza & $1973-2010$ & 1.972 & 1.784 & 0.074 & 1.597 & 1.436 & -0.161 & 0.550 & 0.631 & 0.268 & -0.590 & -0.483 & -1.187 \\
\hline 29 & Shahrkord & $1955-2010$ & -1.328 & -0.805 & -0.751 & -0.134 & -0.859 & -1.315 & -1.556 & -1.644 & -0.879 & -1.355 & -0.604 & 0.027 \\
\hline 30 & Sibak & $1995-2010$ & 0.443 & 2.214 & 2.562 & 2.589 & 1.664 & -1.342 & 0.885 & -0.671 & -1.207 & -1.878 & -1.033 & 0.617 \\
\hline 31 & Singerd & $1976-2010$ & 0.617 & 1.261 & -0.080 & 1.462 & 0.926 & 1.140 & 0.000 & -0.792 & 0.704 & -0.402 & -0.631 & -0.631 \\
\hline 32 & Solegan & $1980-2010$ & -1.892 & -2.254 & -2.267 & 1.529 & 1.476 & 1.221 & 1.650 & 2.435 & 2.522 & -1.878 & -2.173 & -1.905 \\
\hline 33 & Tiran & $1972-2010$ & -1.583 & -1.503 & -0.859 & -0.899 & -0.335 & 0.778 & 2.603 & 2.737 & 3.193 & 1.610 & 2.066 & 1.865 \\
\hline 34 & Varzane & $1961-2010$ & 4.434 & -0.577 & 1.033 & 3.971 & -0.805 & 1.100 & 2.147 & 1.704 & 0.865 & -0.376 & 0.711 & 0.255 \\
\hline 35 & Vazvan & $1971-2010$ & 1.342 & -1.583 & -2.401 & 7.345 & 5.608 & 0.684 & 0.657 & 1.462 & 1.342 & -1.999 & -2.039 & -2.938 \\
\hline 36 & Zamankhan & $1958-2010$ & 1.422 & -0.577 & -1.677 & 1.046 & -0.805 & -1.368 & 0.778 & 1.704 & 1.275 & 1.422 & 0.711 & 0.631 \\
\hline 37 & Zayandehrud & $1967-2010$ & -1.020 & -1.717 & -2.482 & 0.537 & 0.671 & 0.966 & 2.120 & 2.388 & 2.710 & -0.040 & -0.282 & -0.778 \\
\hline \multicolumn{15}{|c|}{ The number of stations with significant increasing and decreasing trend } \\
\hline \multicolumn{3}{|c|}{$\begin{array}{l}\text { The number of stations with } \\
\text { significant decreasing trend }\end{array}$} & 1 & 3 & 10 & 1 & 1 & 0 & 3 & 1 & 0 & 9 & 6 & 2 \\
\hline \multicolumn{3}{|c|}{$\begin{array}{l}\text { The number of stations with } \\
\text { significant increasing trend }\end{array}$} & 18 & 11 & 1 & 16 & 14 & 11 & 18 & 21 & 19 & 1 & 2 & 0 \\
\hline
\end{tabular}

Three parameters of temperature in most stations have increasing trend during fall and summer while indicate a decreasing trend in most stations during winter but few stations have a significant trend. The daily temperature at most stations shows a decreasing trend in the spring while overnight and average temperatures indicate the increasing trend in temperature. Generally, the most significant increasing trend is seen in all three temperature parameters during fall while the least one occurs in winter. Also, the overnight temperature in different seasons is influenced by significant increasing trend more than two other variables.

\section{Temperature Trend at the Climatic Zones}

Equation coefficients and a correlation coefficient of multiple linear regression between the slope of $T_{\max }$, $\mathrm{T}_{\text {mean }}, \mathrm{T}_{\min }$ trends with physiographic parameters 
(altitude, longitude and latitude) are presented in Table 5. In this table, meaningful relationships are shown with a symbol (*). Most relationships are not meaningful, as only the relationship of autumn season for the night and mean temperatures and the relationship of the summer season for daily temperatures are significant. Regarding the weak relationships obtained, it seems that multivariate linear regression is not a suitable method for obtaining the distribution of temperature trend slope in Zayandehrud Basin. Figures 6 to 8 show the result of the IDW interpolation method to prepare a spatial distribution map of temperature trend slope in Zayandehrud basin. In these figures, the stations of the basin with the number of rows listed are shown in Table 3 and 4. Due to the size of the basin and the small number of stations of the basin, the spatial distribution in some areas is obtained as a circular pattern around each station, if it is expected that variation of trend temperature is expected to be gradually distributed at the basin level. According to the weak correlation obtained and the uncertain spatial distribution of the IDW method, it seems that the direct use of the mean values of the temperature trend slope for the stations in each climatic zone as the temperature trend slope of that zone is more logical. The results of trend slope of $\mathrm{T}_{\max }, \mathrm{T}_{\text {mean }}, \mathrm{T}_{\min }$ (averaging method) in the climatic zones of Zayandehrud Basin during different seasons of the year are presented in Fig. 9 to 12. Also, the association of these results with water resources and consumption has been discussed separately in different seasons.

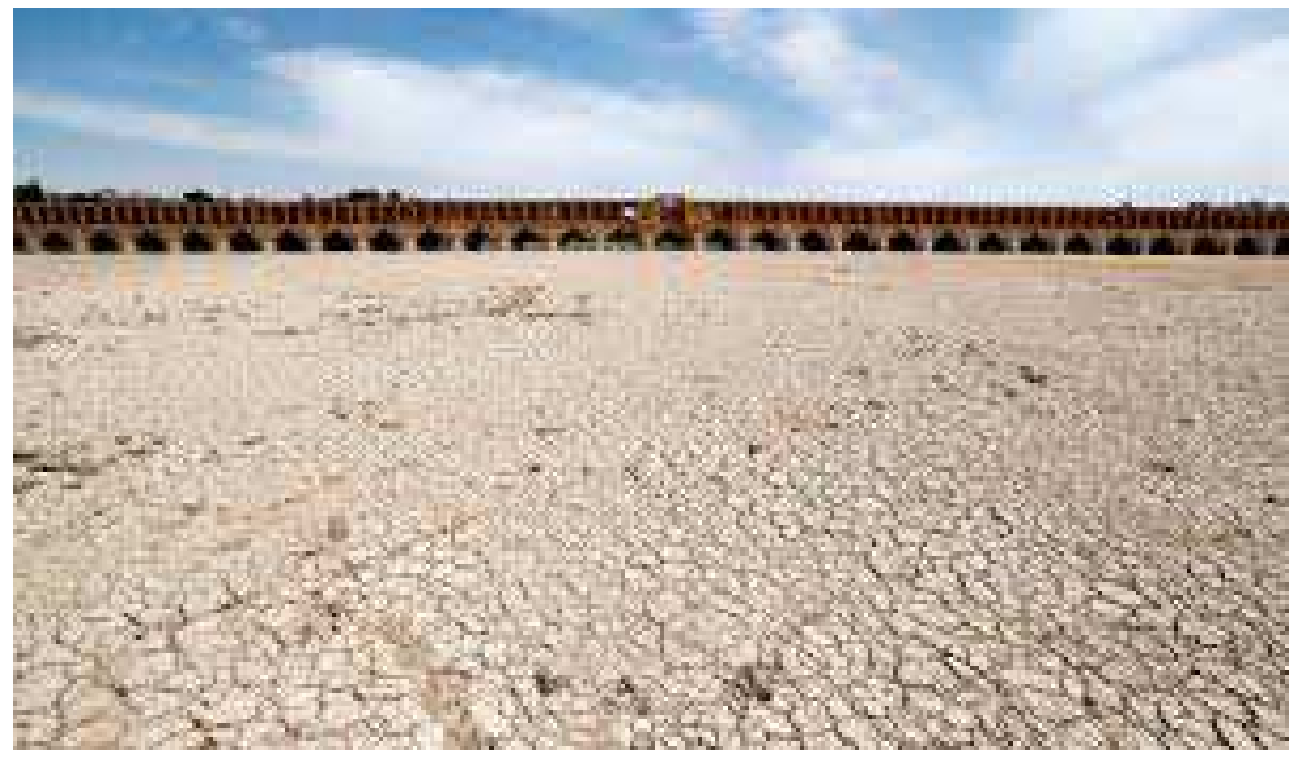

Fig. 5: Drought, wastefulness causes main power lack of Iran's Zayandehrud River Basin
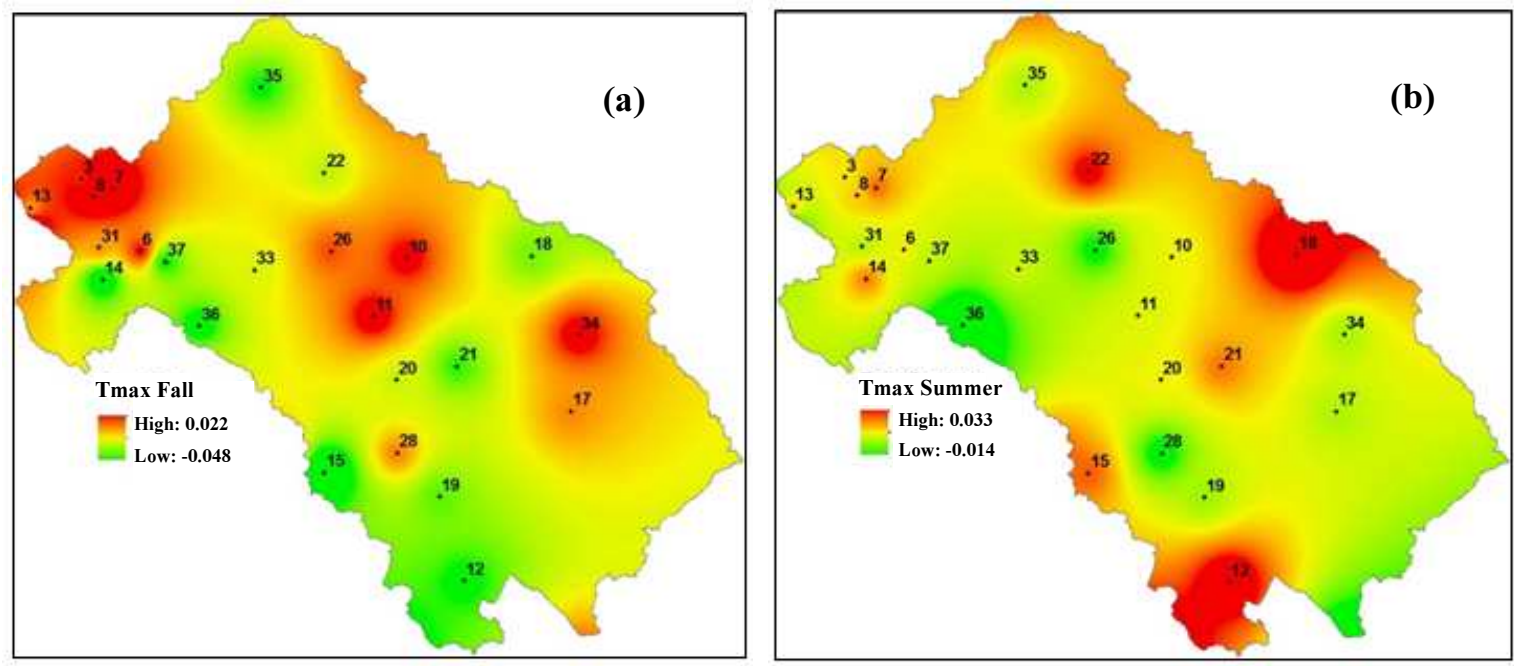

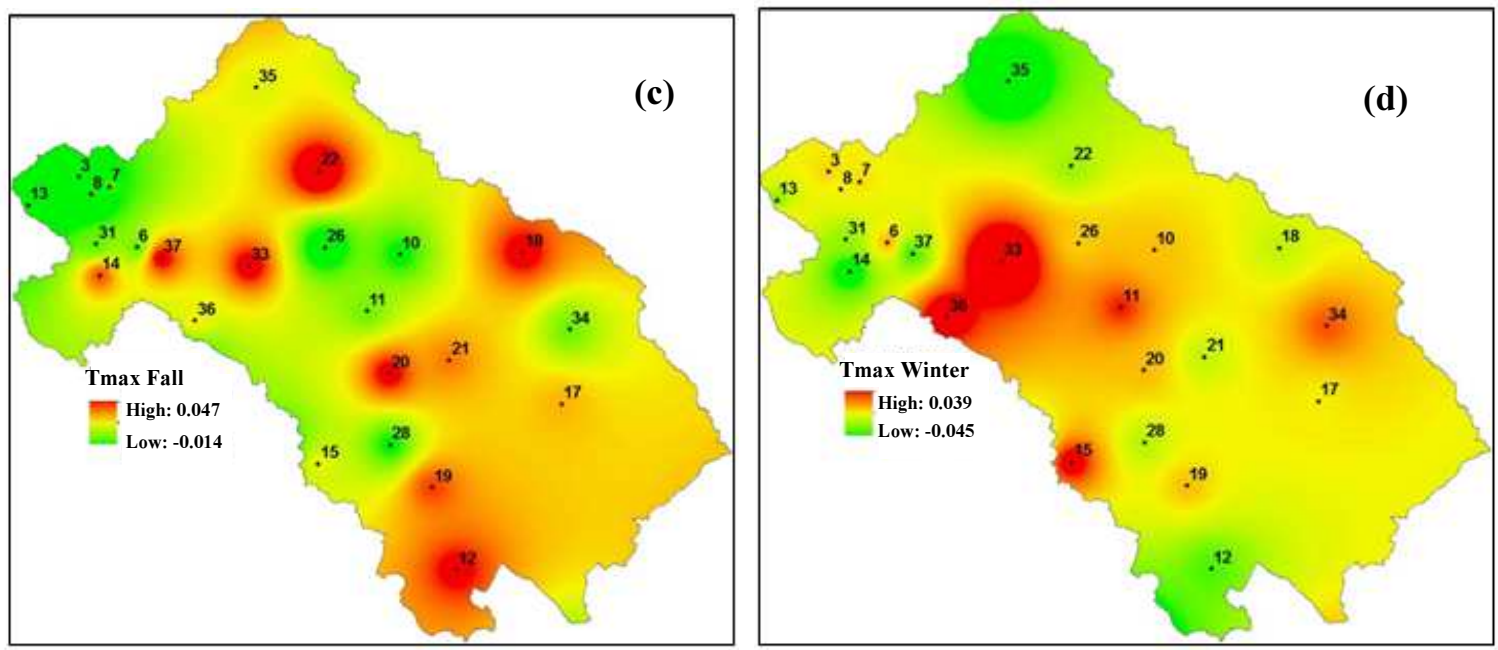

Fig. 6: Spatial distribution map of trend slope of $\mathrm{T}_{\max }$. (a) Spring, (b): Summer, (c): Fall, (d): Winter (The stations of the basin are represented by the row of numbers shown in Tables 3 and 4)
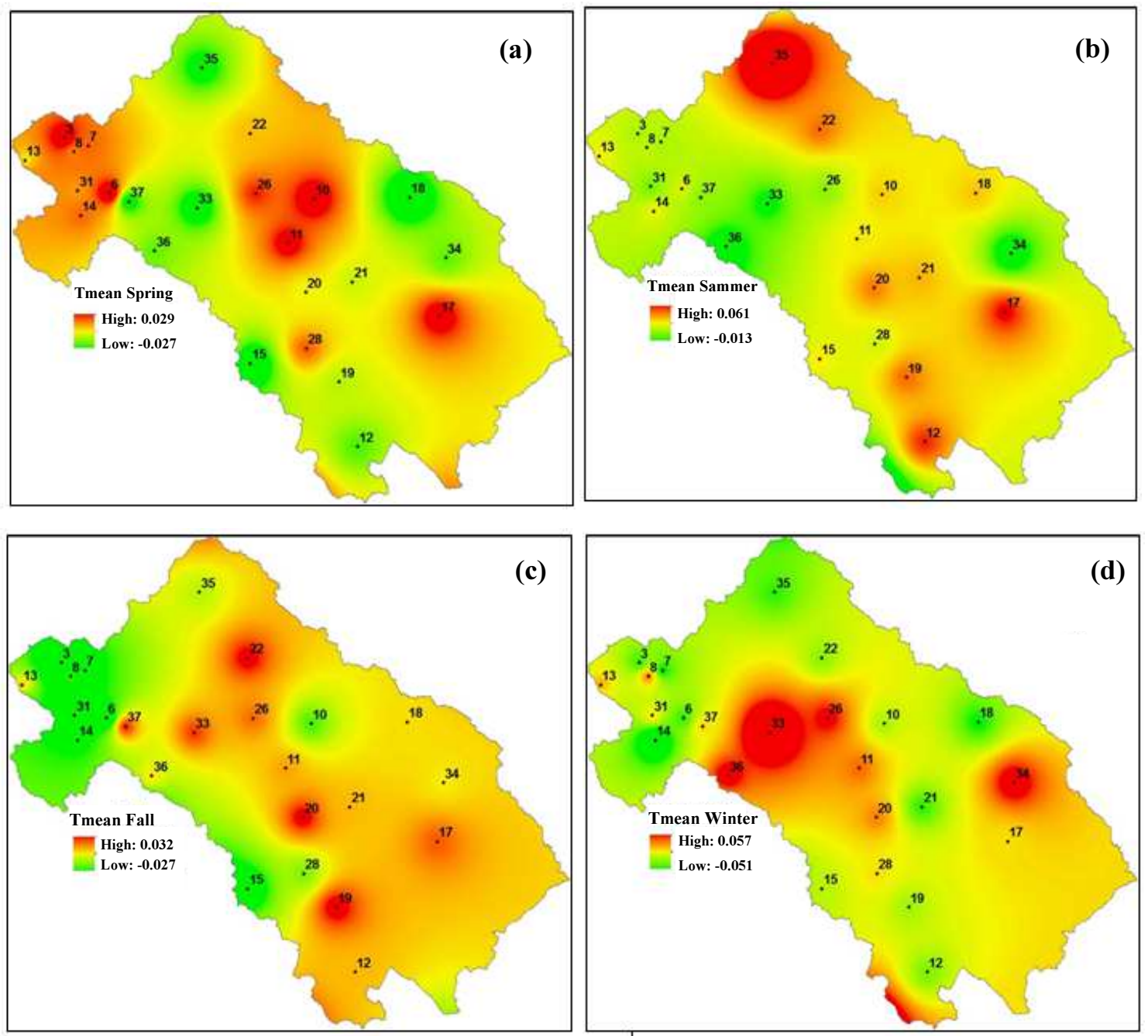

Fig. 7: Spatial distribution map of trend slope of $T_{\max }$. (a): Spring, (b) Summer (c) Fall (d) Winte (The stations of the basin are represented by the row of numbers shown in Tables 3 and 4 


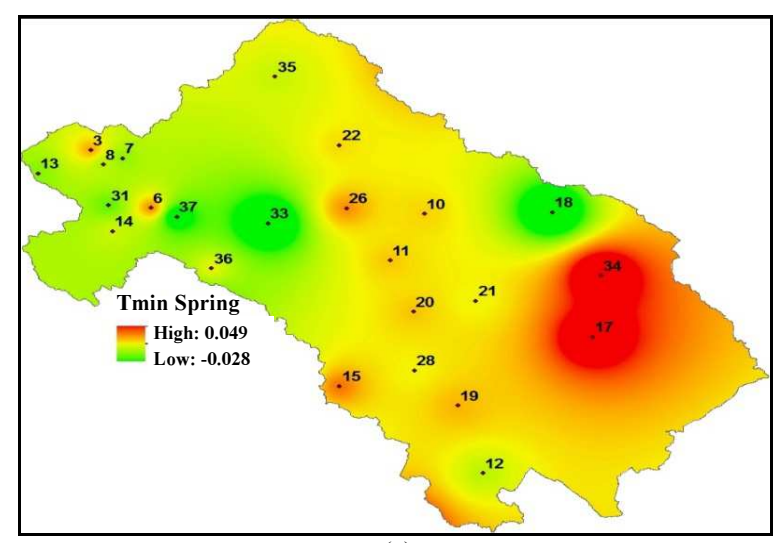

(a)

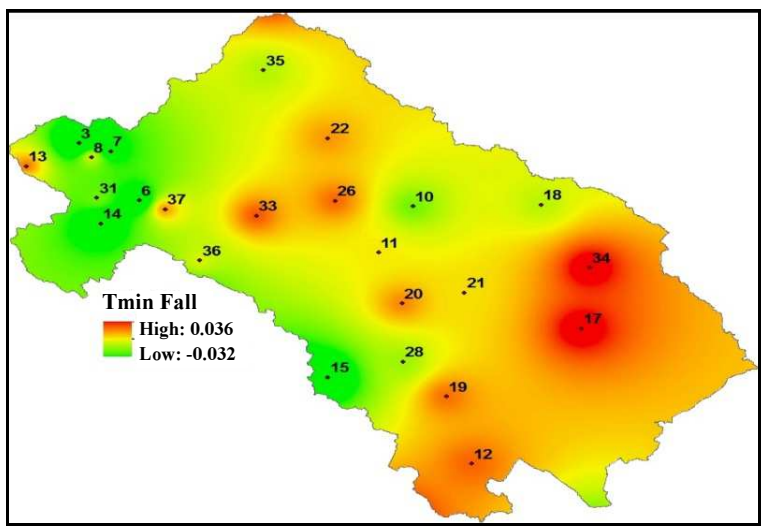

(c)

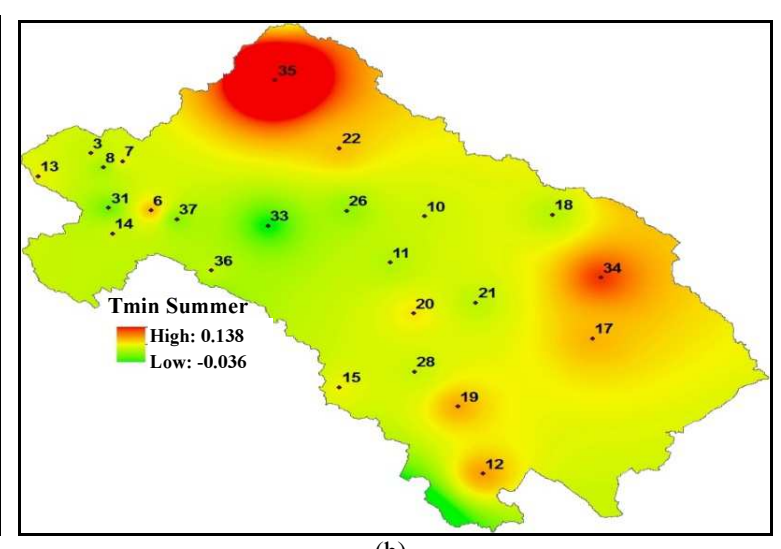

(b)

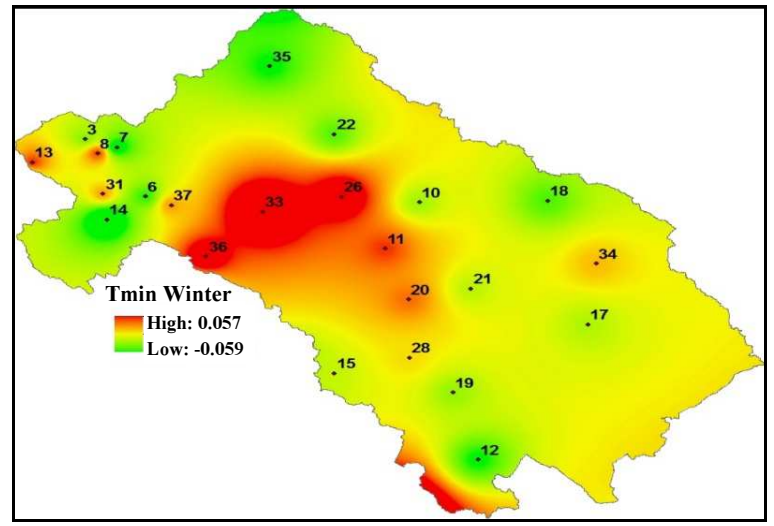

(d)

Fig. 8: Spatial distribution map of trend slope of Tmean (a) Spring (b) Summer (c) Fall (d) Winter (The stations of the basin are represented by the row of numbers shown in Tables 3 and 4)

\section{Spring}

Zayanderud basin will face increasing overnight and average temperature and decreasing daily temperature during spring (Fig. 9). This situation can be seen in all zones of the basin. The maximum rate of rising overnight and average temperature occurs in FK and EG areas while the maximum rate of decreasing daily temperature is seen in the SE area. Peak demand in all areas occurs during spring so increasing consumption caused by rising temperature could lead to significant impact compared to other seasons. Beside high consumption areas like EG and then FK and ND will suffer major deficiency and more pressure to meet the needs. Most runoff is produced in FK area which the maximum volumes occur during spring. Upstream snowmelt begins in FK area during spring. Rising temperature in this season will result in the snow to melt faster and snowpack depletion in early spring and reducing river flow during late spring and summer. This change may not have a significant impact on total inflow into Zayandehrud reservoir but it affects supplying the considerable part of the requirements of FK area in the summer which is related to surface water in the upstream. Reducing the surface flow in FK during summer leads to a problem in meeting the requirements during summer and more pressure on the dam to compensate for the lack of water. In addition, whereas about $25 \%$ of the rainfall in FK area occurs in spring so the rising temperature in this season will help to increase evaporation and decrease soil moisture and runoff inputs to the reservoir and affect water supply in all dependent areas to dam storage (Table 6). High groundwater uses in EG and ND areas with low humidity caused by rising temperatures and reducing the infiltrating rainfall for groundwater may cause the significant deficit. Also, rising temperature in the SE area which is highly dependent upon surface runoff could be effective in runoff reduction and increasing the deficits in the area.

\section{Summer}

All areas of Zayanderud basin experience an increase in daily, overnight and average temperatures during summer (Fig. 10). Meanwhile, the rate of overnight temperature increase is more than daily and average temperature. MM area has the maximum slope of three 
temperature variables and then EG and ND have higher slope compared to other areas. The highest consumption of the basin occurs in the summer after the spring. According to lower consumptions of water in MM and ND areas, they probably face fewer water scarcity problems. Although, EG area has a lower slope compared to MM area, the high consumption of water in this area can result in tougher conditions compared with other areas in the future.

\section{Fall}

All areas of the basin have increasing trend in daily, overnight and average temperature during fall (Fig. 11). Increasing daily temperature slope is more than overnight and average temperature. EG area has the maximum slope of overnight temperature increase while EG, SE and MM areas have the maximum slope of daily and average temperature increase. In this season, the impact of basin warming on consumption will be more obvious in EG area due to the high severity of warming and higher consumption. The highest rainfall of the basin occurs in winter but fall rainfall is important for supplying antecedent soil moisture. Temperature increase leads to rapid evaporation of fall rainfall, reducing soil moisture and decline in fall runoff and even winter runoff. Because of low soil moisture in fall, some winter rainfall would be used for soil moisture supply and reaching saturation point. This can lead to more reducing runoff and increasing deficits in the areas which are independent to surface water such as FK and $\mathrm{SE}$, also reducing runoff (FK area) results in the reduction of reservoir (Zayanderoud) storage and increasing deficits in all areas especially areas that are more dependent on dam storage. Temperature increase and reducing antecedent soil moisture in fall is also effective in the decrease of aquifer feeding in different areas. It seems this is more important in EG and ND areas due to the higher volume of groundwater use (Table 6).

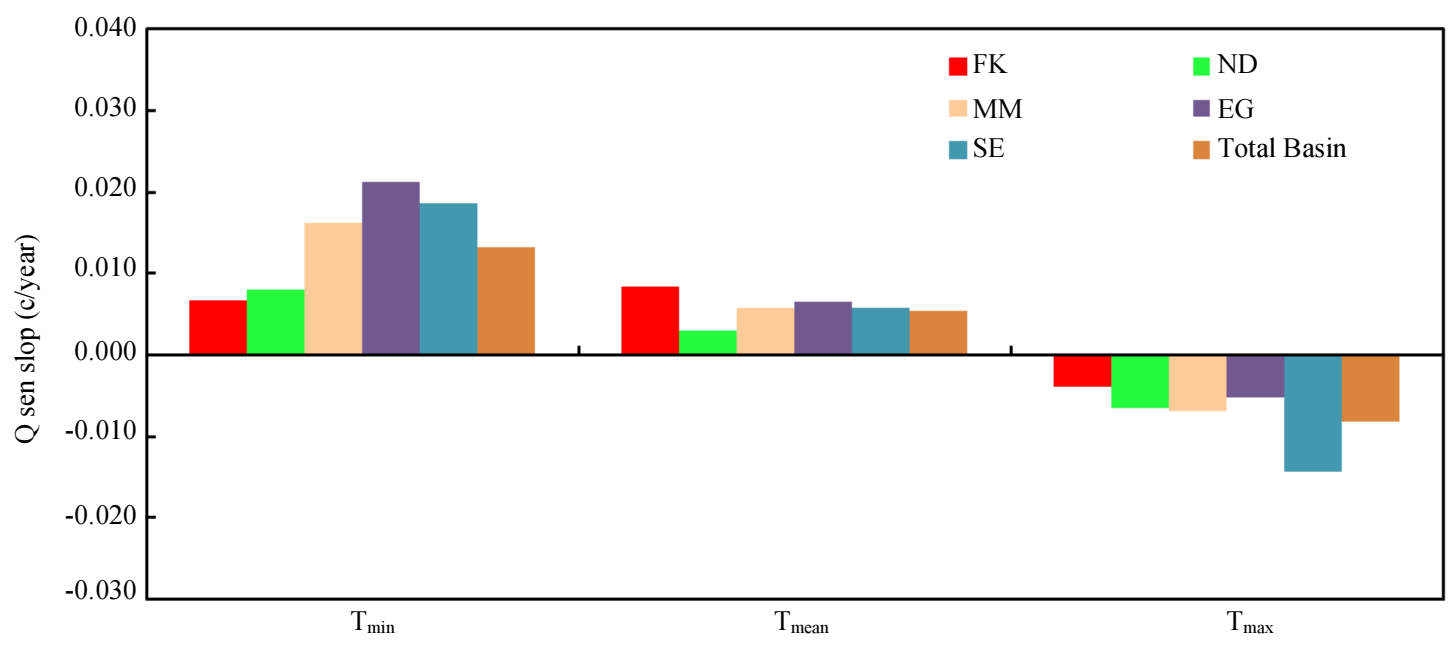

Fig. 9: The average of Q Sen's Slop during spring in different areas of the basin

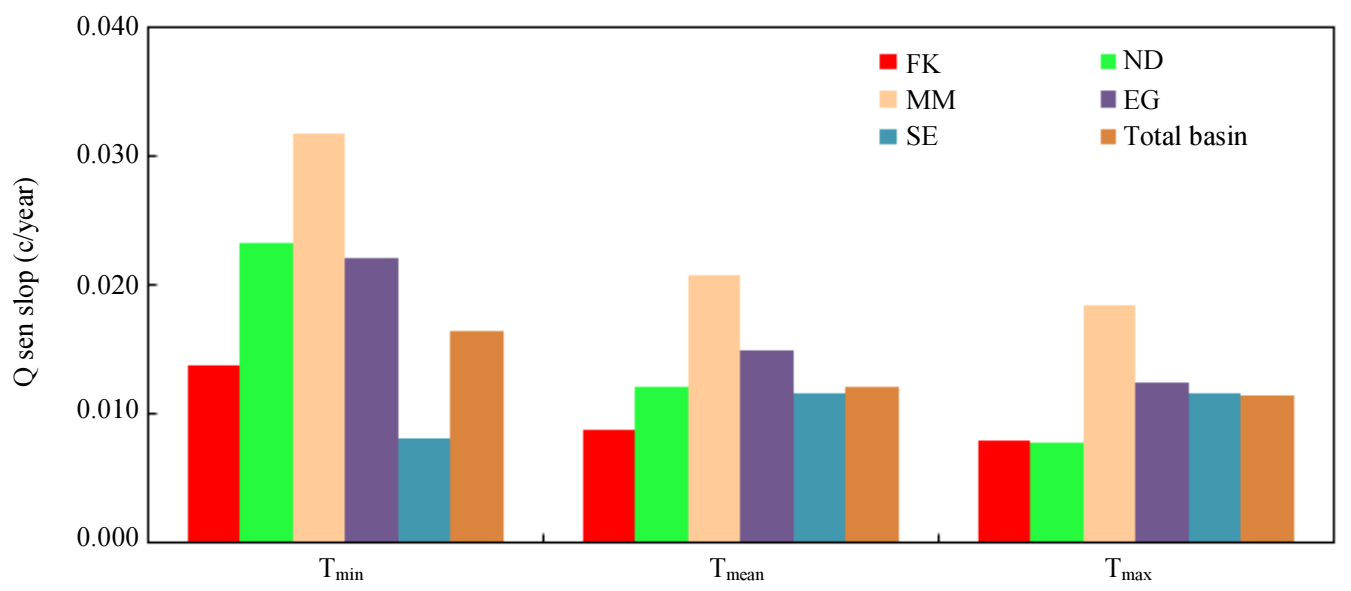

Fig. 10: The average of Q Sen's Slop during summer in different areas of the basin 


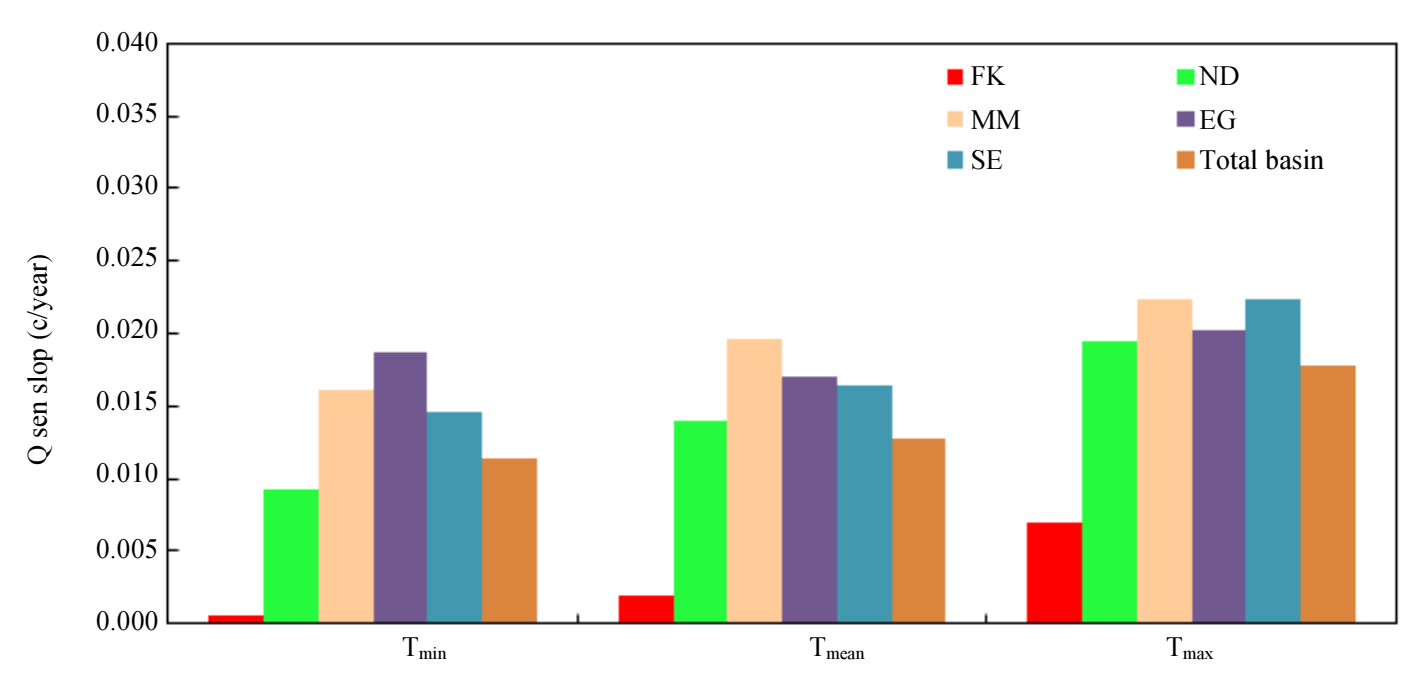

Fig. 11: The average of Q Sen's Slop during fall in different areas of the basin

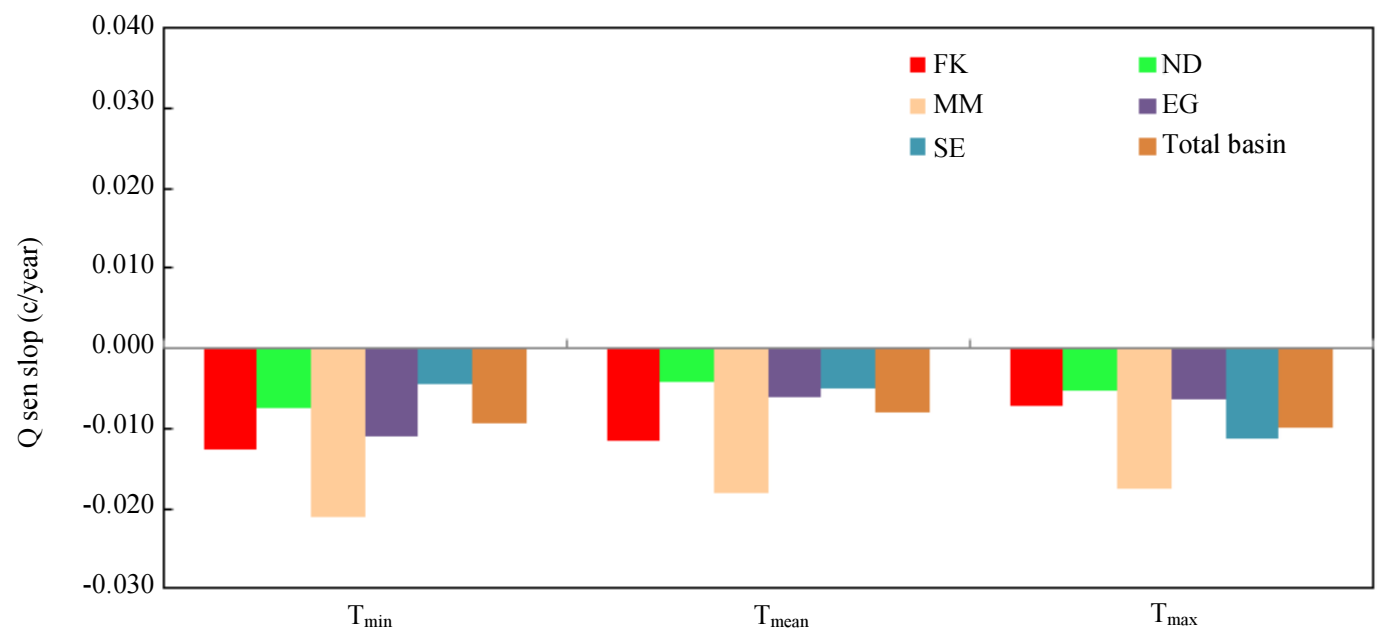

Fig. 12: The average of Q Sen's Slop during winter in different areas of the basin

Table 5: Multiple linear regression coefficients of trend slop with physiographic parameters

\begin{tabular}{llllll}
\hline Temperature & Coefficient & Spring & Summer & Fall* & Winter \\
\hline $\mathrm{T}_{\min }$ & $\mathrm{R}^{2}$ & 0.073 & 0.191 & 0.253 & 0.104 \\
& Constant & -0.027 & -0.858 & -0.155 & 0.774 \\
& Altitude & $-9.50 \mathrm{E}-06$ & $-1.07 \mathrm{E}-06$ & $-2.16 \mathrm{E}-05$ & $-2.84 \mathrm{E}-05$ \\
& Longitude & $3.12 \mathrm{E}-08$ & $1.23 \mathrm{E}-07$ & $4.57 \mathrm{E}-08$ & $-1.24 \mathrm{E}-07$ \\
& Latitude & $1.16 \mathrm{E}-08$ & $2.25 \mathrm{E}-07$ & $5.09 \mathrm{E}-08$ & $-1.83 \mathrm{E}-07$ \\
$\mathrm{~T}_{\max }$ & $\mathrm{R}^{2}$ & 0.075 & 0.316 & 0.147 & 0.122 \\
& Constant & -0.283 & -0.461 & 0.022 & 0.281 \\
& Altitude & $1.22 \mathrm{E}-06$ & $1.76 \mathrm{E}-05$ & $-1.17 \mathrm{E}-05$ & $-2.92 \mathrm{E}-05$ \\
& Longitude & $5.66 \mathrm{E}-09$ & $5.76 \mathrm{E}-08$ & $5.16 \mathrm{E}-08$ & $-9.41 \mathrm{E}-08$ \\
& Latitude & $7.47 \mathrm{E}-08$ & $1.13 \mathrm{E}-07$ & $-2.47 \mathrm{E}-09$ & $-5.08 \mathrm{E}-08$ \\
$\mathrm{~T}_{\operatorname{mean}}$ & $\mathrm{R}^{2}$ & 0.01 & 0.166 & 0.222 & 0.126 \\
& Constant & 0.042 & -0.404 & -0.028 & 0.601 \\
& Altitude & $-5.51 \mathrm{E}-06$ & $-1.27 \mathrm{E}-06$ & $-1.94 \mathrm{E}-05$ & $-2.90 \mathrm{E}-05$ \\
& Longitude & $-2.61 \mathrm{E}-08$ & $5.87 \mathrm{E}-08$ & $3.20 \mathrm{E}-08$ & $-9.84 \mathrm{E}-08$ \\
& Latitude & $-3.18 \mathrm{E}-09$ & $1.07 \mathrm{E}-07$ & $1.72 \mathrm{E}-08$ & $-1.39 \mathrm{E}-07$ \\
\hline
\end{tabular}


Table 6: Contribution to water consumption of each zone from groundwater and surface water resources and Zayanderud reservoir $(\mathrm{mcm})($ Source: Ministry of energy)

\begin{tabular}{lccc}
\hline Area & Surface water & Groundwater & Zayanderud reservoir \\
\hline FK & 108 & 42 & 229 \\
ND & 0 & 118 & 374 \\
MM & 0 & 13 & 38 \\
SE & 153 & 35 & 6 \\
EG & 0 & 95 & 878 \\
\hline
\end{tabular}

\section{Winter}

Generally, winter in Zayandehrud river basin is cooling (Fig. 12). The values of trend slope show temperature reduction (all three variables). This situation can be seen in all areas of the basin. Cooling during winter is occurring in MM and FK areas faster than other areas. Meteorological data shows the most rainfall is observed in FK area which about $50 \%$ falls as snow but the amount of snow is not considered in other areas. Decrease in temperature during the winter will help to increase snowfall and river discharge. On the other hand, it's expected that soils absorb less rainfall and more surface runoff enter the reservoir during this season because of temperature drop and stabilizing moisture content of the soil. This can lead to reducing the deficits in all areas especially areas that are dependent on the storage of Zayandehrud reservoir. Meanwhile, SE area which has considerable surface water resources will probably face increasing surface flow and groundwater will be recharged more during the winter rains.

\section{Review of Trends in the Temperature}

Comparison of Fig. 9 to 12 shows the speed of increasing temperature variables in different zones of the basin is higher in the summer and autumn seasons than in other seasons. Also, the speed of decreasing temperature variables in winter is more than in other seasons.

The maximum slope trend for $\mathrm{T}_{\min }$ is $0.032^{\circ} \mathrm{C} /$ year and for $\mathrm{T}_{\text {mean }}$ is $0.021^{\circ} \mathrm{C} /$ year which happens in $\mathrm{MM}$ area during summer. The amount of $\mathrm{T}_{\max }$ is $0.023^{\circ} \mathrm{C} /$ year and happens during fall in the SE area. While the minimum temperature trend slope happens in the winter which $\mathrm{T}_{\text {min }}$ is $-0.021^{\circ} \mathrm{C} /$ year and $\mathrm{T}_{\max }$ is $-0.018^{\circ} \mathrm{C} /$ year and occur in $\mathrm{MM}$ area. Also, the amount of $\mathrm{T}_{\text {mean }}$ is $-0.018^{\circ} \mathrm{C} /$ year and occurs in FK area during the winter.

\section{Conclusion}

This study aims to investigate trends of daily, overnight and average temperature in climatic zones of the basin and its possible effect on water resource and consumption. So, temperature data from 37 weather stations were collected and evaluated. Then, the temperature trend and magnitude of the trend slope was analyzed using the Mann-Kendall method and Q Sen's Slop estimator. Evaluation of trend in the stations showed that three parameters of temperature (overnight, daily and average temperatures) at most stations have an upward trend in the fall and the summer while indicate decreasing trend during winter and the most significant increasing trend occurs during fall.

study of trends in climatic zones of the basin (during spring) shows there is an increasing trend in overnight and average temperature and decrease trend in daily temperature in all areas of the basin. Also, the maximum rate of rising of the overnight and average temperature occurs in FK and EG and the maximum rate of decrease in daily temperature in SE. During summer, it is shown an increase in three temperature variables all areas of the basin which MM has the maximum slope while during fall there is an increase in three temperature variables with faster increasing of overnight temperature in EG and more rapid increase in daily and an average temperature in EG, SE and MM. During winter, there is a decrease in trend slope for all three temperature variables which MM in all areas and FK have the maximum rate. According to the above mentioned the results show the most rate of increasing temperature is observed in summer and fall (in the Zayandehrud basin) while the most rate of decreasing temperature occurs in winter.

Studying the possible effect of various trends of the temperature on water resources in different zones shows an increase in fall and spring temperatures in FK and reducing input flow to the reservoir (Zayandehrud), will put the most pressure on EG which is the most dependent on the reservoir. The effect of groundwater resources due to an increase in fall and spring temperature on the deficit in EG and ND will be observed clearly in these areas because of the considerable volume of groundwater use. Increasing fall and spring temperatures in SE is more remarkable than the other areas due to the considerable volume of water use and the biggest dependence on surface water resources. The temperature drop occurs in all areas that are effective in increasing surface flow and aquifer feeding. Increasing snowfall and runoff reservoir in FK has a significant effect on decreasing the deficits dependent area on the dam. The consumptions results show that rising temperature during summer, spring and fall could lead to increased consumption in all areas that seem water supply situation is more difficult in high demand areas during hot months (summer and spring). All in all, SE, MM and EG have the maximum slope of temperature among different zones of the basin. 
Thus, EG which is the highest demand area of the basin probably experience a tougher situation to meet the requirements. In addition, immigration to this area and population growth will worsen the conditions of the area in the future. The temperature increase in fall, spring and summer mark the decrease of water resources and cumulative feeding in various zones. Among the different places, the Eastern portion of the washbasin will be encountered with more water pressure to visit their requires. The conclusions of this article can be actual for an proof of identity of penetrating places to climate change in the basin and preparation to controller water pressure and attaining maintainable river basin administration. The rising temperature and humidity trends are also reliable with rising trends in superficial temperature, a amount of human relief depend on temperature and humidity. Relative humidity inclinations are frailer than the specific humidity trends, but they do display sign of increases, particularly in winter and spring. The opportunity that the noticed trends may be artifacts of alterations in arrangement was scrutinized, but several lines of reasoning recommend that they are not.

\section{Acknowledgment}

This research was supported by the Isfahan University of the Technology. We thank our all authors who provided insight and expertise that greatly assisted the research.

\section{Author's Contributions}

All authors contributed to design the study, write and revise the manuscript.

\section{Ethics}

The present Study and ethical aspect were approved by the Isfahan University of the Technology. The present study was approved by the Isfahan University of Technology.

\section{References}

Ahmadi, A., A. Khoramian and H.R. Safavi, 2015. Assessment of climate change impacts on snowrunoff processes a case study: Zayanderud river Basin (In Persian). Iran-Water Resources Res., 11: 70-82.

Ahmed, S.I., R. Rudra, T. Dickinson and M. Ahmed, 2014. Trend and periodicity of temperature time series in Ontario. Am. J. Climate Change, 3: 272288. DOI: $10.4236 /$ ajcc.2014.33026

Ataei, H., S. Hasheminasab and S. Cheraghi, 2013. Trend analysis of the average monthly temperature in Isfahan province. Bull. Environ. Pharmacol. Life Sci., 3: 98-102.
Azaranfar, A., A. Abrisham and M. Tajreshi, 2009. Analysis of impact of climate change in precipitation and temperature in Zayandehrud Basin. Proceedings of the 4th Iranian National Conference on Water Resources, (CWR' 09), Tehran, Iran.

Boccolari, M. and S. Malmusi, 2013. Changes in temperature and precipitation extremes observed in Modena, Italy. Atmos. Res., 122: 16-31. DOI: 10.1016/j.atmosres.2012.10.022

Booij, M.J., D. Tollenaar, E. van Beek, J.C.J. Kwadijk, 2011. Simulating impacts of climate change on river discharges in the Nile basin. J. Hydrol., 36: 696-709. DOI: $10.1016 /$ j.pce.2011.07.042

Cai, W. and T. Cowan, 2008. Evidence of impacts from rising temperature on inflows to the Murray-Darling Basin. Geophys. Res. Lett., 35: L07701-L07701. DOI: 10.1029/2008GL033390

Chen, C., E. Wang and Q. Yu, 2010. Modeling the effects of climate variability and water management on crop water productivity and water balance in the North China Plain. Agric. Water Manage., 97: 117584. DOI: $10.1016 /$ j.agwat.2008.11.012

Chowdhury, S. and M. Al-Zahrani, 2015. Characterizing water resources and trends of sector wise water consumptions in Saudi Arabia. J. King Saud Univ. Eng. Sci., 27: 68-82. DOI: $10.1016 /$ j.jksues.2013.02.002

Christensen, N.S., A.W. Wood, N. Voisin, D. Lettenmaier and R.N. Palmer, 2004. The effects of climate change on the hydrology and water resources of the Colorado River Basin. Clim. Change, 62: 337-363. DOI: 10.1023/B:CLIM.0000013684.13621.1f

Dastorani, M.T. and S. Poormohammadi, 2016. Mapping of climatic parameters under climate change impacts in Iran. Chem. Ecol. Hydrol. Sci. J. DOI: $10.1080 / 02626667.2015 .1131898$

Eslamian, S.S., K.L. Gilroy and R.H. McCuen, 2012. Climate change detection and modeling in hydrology. Climate change-research and technology for adaptation and mitigation. In Tech.

Gandomkar, A., 2011. Investigating the precipitation and temperature change procedure in Zayanderood waters. Int. J. Environ. Chem. Ecol. Geol. Geophys. Eng., 5: 494-499.

Ghahraman, B., 2006. Time trend in the mean annual temperature of Iran. Turk. J. Agric. For., 30: 439-448.

Ghasemi, A.R., 2015. Changes and trends in maximum, minimum and mean temperature series in Iran. Atmos. Sci. Let., 16: 366-372.

Gleick, P.H., 1987a. The development and testing of a water balance model for climate impact assessment: Modeling the Sacramento basin. Water Resources Res., 23: 1049-1061. DOI: 10.1029/WR023i006p01049 
Gleick, P.H., 1987b. Regional hydrologic consequences of increases in atmospheric $\mathrm{CO}_{2}$ and other trace gases. Climatic Change, 10: 137-161.

DOI: $10.1007 / \mathrm{BF} 00140252$

Gocic, M. and S. Trajkovic, 2013. Analysis of changes in meteorological variables using Mann-Kendall and Sen's Slope estimator statistical tests in Serbia. Global Planetary Change, 100: 172-182.

DOI: 10.1016/j.gloplacha.2012.10.014

Gohari, A., S. Eslamian, J. Abedi-Koupai, A. MassahBavani and D. Wang et al., 2013. Climate change impacts on crop production in Iran's Zayandeh-Rud River Basin. Sci. Total Environ., 442: 405-419. DOI: 10.1016/j.scitotenv.2012.10.029

Grieser, J., S. Tromel and C.D. Schonwiese, 2002. Statistical time series decomposition into signification components and application to European temperature. Theor. Applied. Climatol., 71: 171-183. DOI: 10.1007/s007040200003

Hasanean, H.M., 2001. Fluctuations of surface air temperature in the Eastern Mediterranean. Theor. Applied Climatol., 68: 75-87. DOI: $10.1007 / \mathrm{s} 007040170055$

IPCC, 2013. Climate Change 2013: The Physical Science Basis. In: Contribution of Working Group I to the Fifth Assessment Report of the Intergovernmental Panel on Climate Change, Stocker, T.F., D. Qin, G.K. Plattner, M. Tignor and S.K. Allen et al. (Eds.), Cambridge University Press, Cambridge, UK, pp: 15-35.

Islam, A.W., 2015. Rainy/non-rainy day pattern analysis for North Carolina. Am. J. Climate Change, 4: 1-8. DOI: $10.4236 /$ ajcc. 2015.41001

Jaagus, J., 2006. Climatic changes in Estonia during the second half of the 20th century in relationship with changes in large-scale atmospheric circulation. Theor. Applied Climatol., 83: 77-88.

DOI: $10.1007 / \mathrm{s} 00704-005-0161-0$

Kendall, M.G., 1975. Rank Correlation Measures. Charles Griffin, London.

Kouhestani, S., S.S. Eslamian, J. Abedi-Koupai and A. Asghar Besalatpour, 2016. Projection of climate change impacts on precipitation using soft-computing techniques: A case study in Zayandeh-rud Basin, Iran. Global Planetary Change, 144: 158-170. DOI: 10.1016/j.gloplacha.2016.07.013

Mann, H.B., 1945. Non-parametric tests against trend. Econometrica, 13: 245-259.

Martinez, M.D., C. Serra, A. Burgueno and X. Lana, 2010. Time trends of daily maximum and minimum temperatures in Catalonia (ne Spain) for the period 1975-2004. Int. J. Climatol., 30: 267-290.

Matouq, M., T. El-Hasan, H. Al-Bilbisi, M. Abdelhadi and M. Hindiyeh et al., 2013. The climate change implication on Jordan: A case study using GIS and Artificial Neural Networks for weather forecasting. J. Taibah Univ. Sci., 7: 44-55.

DOI: $10.1016 /$ j.jtusci.2013.04.001
McCallum, J.L., 2010. Impacts of climate change on groundwater in Australia: A sensitivity analysis of recharge. Hydrogeol. J., 18: 1625-1638.

DOI: $10.1007 / \mathrm{s} 10040-010-0624-\mathrm{y}$

Montazeri, M. and M. Karimpur, 2011. climatic zones detection using multi-variable methods in Zayandehrud basin (In Persian). J. Natural Geography, 14: 103-116.

Nie, C., H. Li, L. Yang, B. Ye and E. Dai et al., 2012. Spatial and temporal changes in extreme temperature and extreme precipitation in Guangxi. Quater. Int., 263: 162- 171. DOI: 10.1016/j.quaint.2012.02.029

Perez, J.F., L. Gimeno, P. Ribera, D. Gallego and R. Garia et al., 2000. Influence of the orth Atlantic oscillation on winter equivalent temperature. Proceedings of the AGU Chapman Conference of "The North Atlantic Oscillation", (NAO' 00), University of Vigo (Orense campus), Orense, Galicia, Spain.

Romero-Higareda, C.E., L.I. Peinado-Guevara, S. Campista-Lén, J. Cázarez-Martínez and J.G. Sánchez-Zazueta et al., 2014. Temperature trend analysis in the North Pacific watershed in Mexico. Am. J. Climate Change, 3: 306-325. DOI: $10.4236 /$ ajcc.2014.33028

Rosenberg, N.J., D.J. Epstein, D. Wang, L. Vail and R. Srinivasan et al., 1999 .Possible impacts of global warming on the hydrology of the Ogallala aquifer region. Climatic Change, 42: 677-692.

DOI: $10.1023 / \mathrm{A}: 1005424003553$

Roshan, G.R., F. Khoshakhlagh, G. Azizi and H. Mohammadi, 2011. Simulation of temperature changes in Iran under the atmosphere carbon dioxide duplication condition, Iran. J. Environ. Health. Sci. Eng., 8: 139-152.

Safavi, H.R., M.H. Golmohammadi and S. SandovalSolis, 2015. Expert knowledge based modeling for integrated water resources planning and management in the Zayandehrud River Basin. J. Hydrol., 528: 773-789.

Safavi, H.R., M.H. Golmohammadi and S. SandovalSolis, 2016. Scenario analysis for integrated water resources planning and management under uncertainty in the Zayandehrud river basin. J. Hydrol., 539: 625-639.

DOI: $10.1016 /$ j.jhydrol.2016.05.073

Sayemuzzaman, M., M.K. Jha and A. Mekonnen, 2014. Spatio-temporal long-term (1950-2009) temperature trend analysis in North Carolina, United States. Theor. Applied Climatol., 116: 3-4.

Schlenker, W. and D.B. Lobell, 2010. Robust negative impacts of climate change on African agriculture. Environ. Res. Lett., 5: 1-8. DOI: $10.1088 / 1748-9326 / 5 / 1 / 014010$ 
Schlunzen, K.H., P. Hoffmann, G. Rosenhagen and W. Riecke, 2010. Long-term changes and regional differences in temperature and precipitation in the metropolitan area of Hamburg. Int. J. Climatol., 30: 1121-1136. DOI: 10.1002/joc.1968

Sen, P.K., 1968. Estimates of the regression coefficient based on Kendall's Tau. J. Am. Stat. Assoc., 63: 1379-1389.

DOI: $10.1080 / 01621459.1968 .10480934$

Stewart, I.T., D.R. Cayan and M.D. Dettinger, 2004. Changes in snowmelt runoff timing in western north America under 'Business as usual' climate change scenario. Climate Change J., 62: 217-232. DOI: 10.1023/B:CLIM.0000013702.22656.e8

Tabari, H. and P. Hosseinzadeh-Talaee, 2011. Analysis trends in temperature data in arid and semi-arid regions of Iran. Atmos. Res., 79: 1-10.

Tabari, H. and S. Marofi, 2011. Changes of Pan evaporation in the west of Iran. Water Resour. Manage., 25 97-111.

DOI: $10.1007 / \mathrm{s} 11269-010-9689-6$

Tabari, H., P. Hosseinzadeh, A. Ezani and B. Shifteh, 2012. Shift changes and monotonic trends in auto correlated temperature series over Iran. Theor. Applied Climatol., 109: 95-108.

DOI: 10.1007/s00704-011-0568-8

Takara, K., S. Kim, Y. Tachikawa and E. Nakakita, 2009. Assessing climate change impact on water resources in the tone River Basin, Japan using super-high-resolution atmospheric model output. J. Disaster Res., 4: 12-23. DOI: $10.20965 /$ jdr.2009.p0012

Turkes, M. and U.M. Sumer, 2004. Spatial and temporal patterns of trends and variability in diurnal temperature ranges of Turkey. Theor. Applied Climatol., 77: 195-227.

DOI: $10.1007 / \mathrm{s} 00704-003-0024-5$
Wang, Q.H., X.H. Fan, Z.D. Qin and M.B. Wang, 2012. Change trends of temperature and precipitation in the Loess Plateau Region of China, 1961- 2010. Global Planet Change, 93: 138-147.

DOI: $10.1016 /$ j.gloplacha.2012.05.010

Woodhouse, C.A., G.T. Pederson, K. Morino, S.A. McAfee and G.J. McCabe, 2016. Increasing influence of air temperature on upper Colorado River stream flow. Geophys. Res. Lett. DOI: $10.1002 / 2015$ GL067613

$\mathrm{Xu}$, C.Y., L. Gong, T. Jiang, D. Chen and V.P. Singh, 2006. Analysis of spatial distribution and temporal trend of reference evapotranspiration in Changjiang (Yangtze River) Catchment. J. Hydrol., 327: 81-93. DOI: 10.1016/j.jhydrol.2005.11.029

Yazdani, M.R., J. Khoshhal Dastjerdi, M. Mahdavi and S. Ashish, 2011 Trend detection of the rainfall and air Temperature data in the Zayandehrud Basin. J. Applied Sci., 11: 2125-2134. DOI: 10.3923/jas.2011.2125.2134

Yazdanpanah, H., H. Barghi and A. Esmaili, 2016. Effect of climate change impact on tourism: A study on climate comfort of Zayandehroud River route from 2014 to 2039. Tourism Manage. Perspectives, 17: 82-89. DOI: 10.1016/j.tmp.2015.12.002

Yue, S. and M. Hashino, 2003. Temperature trends in Japan: 1900-1996. Theor. Applied Climatol., 75: 1527. DOI: $10.1007 / \mathrm{s} 00704-002-0717-1$

Zareian, M.J., S. Eslamian, H.R. Safavi and A. Eslamian, 2015. Effect of climate change on reference evapotranspiration based on weighting methods. Proceedings of the 4th Climate Change Technology Conference, (CTC' 15), Canada, Montreal.

Zarenistanak, M., A.G. Dhorde and R.H. Kripalani, 2014. Temperature analysis over southwest Iran: Trends and projections. Theor. Applied Climatol., 116: 103-117. DOI: 10.1007/s00704-013-0913-1 